\title{
Correspondence
}

\section{The diagnostic value of polymerase chain reaction in erythema induratum of Bazin}

SIR, Erythema induratum of Bazin (EIB) is a chronic, nodular eruption that usually occurs on the lower legs of women with tuberculin hypersensitivity. The aetiopathogenetic association between EIB and tuberculosis is still controversial. ${ }^{1}$

A 38-year-old woman presented with recurrent crops of tender, painful, non-ulcerating erythematous nodules occurring on the lower third of her left calf and shin over the last 5 years (Fig. 1). She had no personal or family history of active tuberculosis and had received a BCG vaccination during childhood. Forty-eight hours after a purified protein derivative test, an erythematous induration of $2.5 \mathrm{~cm} \times 2.5 \mathrm{~cm}$ was observed at the test site. Tests for the diagnosis of tuberculosis showed a normal chest X-ray, and were negative for acidfast bacilli in the sputum. Mycobacterial culture of a skin specimen and sputum proved negative, and bacterial culture of the skin specimen was also negative. Histopathology revealed an infiltration of mononuclear cells which was most prominent in the fat lobules, multinucleate giant cell granulomas and perivascular inflammation in some areas of the subcutis. Ziehl-Neelsen staining for acid-fast bacilli was negative.

To investigate the possible relationship between EIB and Mycobacterium tuberculosis, polymerase chain reaction (PCR) of the biopsy specimen was carried out using a method described by Eisenach et al. ${ }^{2}$ The biopsy specimen was digested in a buffer $(200 \mu \mathrm{g} / \mathrm{mL}$ proteinase $\mathrm{K}$ in $50 \mathrm{mmol} / \mathrm{L}$ Tris-HCl $\mathrm{pH} 8.5$ ) for $6 \mathrm{~h}$ at $55^{\circ} \mathrm{C}$ and boiled for $10 \mathrm{~min}$. Phenolchloroform extraction was performed and ethanol precipitated DNA was resuspended in TE buffer $(10 \mathrm{mmol} / \mathrm{L}$ Tris $-\mathrm{HCl}$, $1 \mathrm{mmol} / \mathrm{L}$ ethylenedianine tetraacetic acid, $\mathrm{pH} \mathrm{7 \cdot 4)}$ and used for amplification. The sequences of the primers $\left(5^{\prime}\right.$ to $\left.3^{\prime}\right)$ were CCTGCGAGCGTAGGCGTCGG and CTCGTCCAGCGCCGCTTCGG. Amplification reactions were performed by using Taq polymerase and reagents according to the manufacturer's instructions (Promega, Madison, WI, U.S.A.). Five microlitres of DNA were added to the mixture. The reaction was run for 40 cycles with denaturation at $94^{\circ} \mathrm{C}$ for $2 \mathrm{~min}$, annealing at $68^{\circ} \mathrm{C}$ for $2 \mathrm{~min}$ and extension at $72^{\circ} \mathrm{C}$ for $2 \mathrm{~min}$ in a thermal cycler (MJ Research, Watertown, MA, U.S.A.). PCR products were analysed by gel electrophoresis on a $2 \%$ agarose gel stained with ethidium bromide and visualized by ultraviolet light. A PCR product of $123 \mathrm{bp}$ diagnostic for M. tuberculosis DNA was obtained (Fig. 2). The patient was given antituberculosis chemotherapy consisting of isoniazid, rifampicin and pyrazinamide and was free of lesions after the first month of treatment.

Tuberculosis is still a very important infectious disease world-wide, especially in developing countries. Early detection and accurate diagnosis of tuberculosis and related diseases are of major importance in the control of this disease. EIB has been accepted as a type of tuberculid that usually occurs on the legs of middle-aged women, possibly after haematogenous spread of a few mycobacteria. ${ }^{1,3}$ The tuberculous origin of EIB is controversial since mycobacteria cannot be cultured from the skin lesions. ${ }^{1,3}$

EIB is one of a group of diseases that primarily involve the legs and are characterized by the presence of inflammatory nodules. These diseases have many clinical and/or histopathological features in common (e.g. EIB, erythema nodosum, nodular vasculitis, pernio, polyarteritis nodosa, subacute nodular migratory panniculitis, syphilitic gummata and recurrent idiopathic thrombophlebitis). ${ }^{1,3}$ It may sometimes therefore be difficult to reach the diagnosis of EIB.
Figure 1. Erythema induratum of Bazin. Non-ulcerating erythematous nodules can be seen on the calf. The punch biopsy site is on the right.

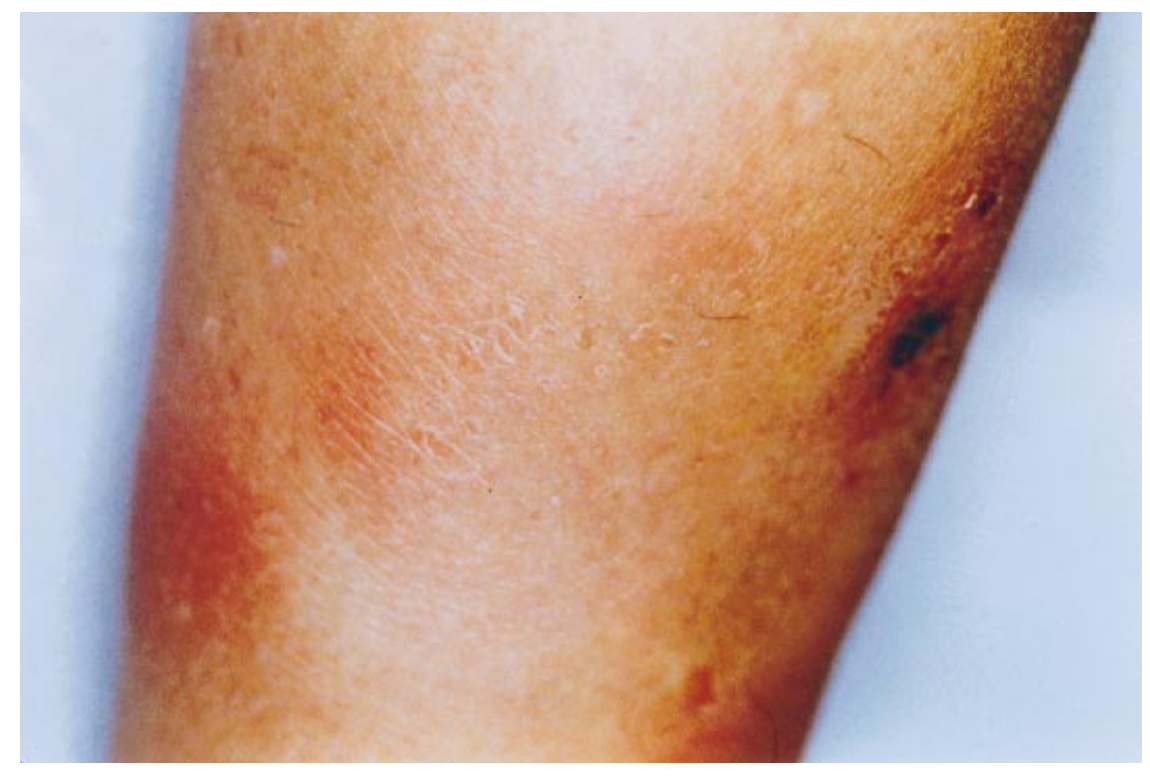




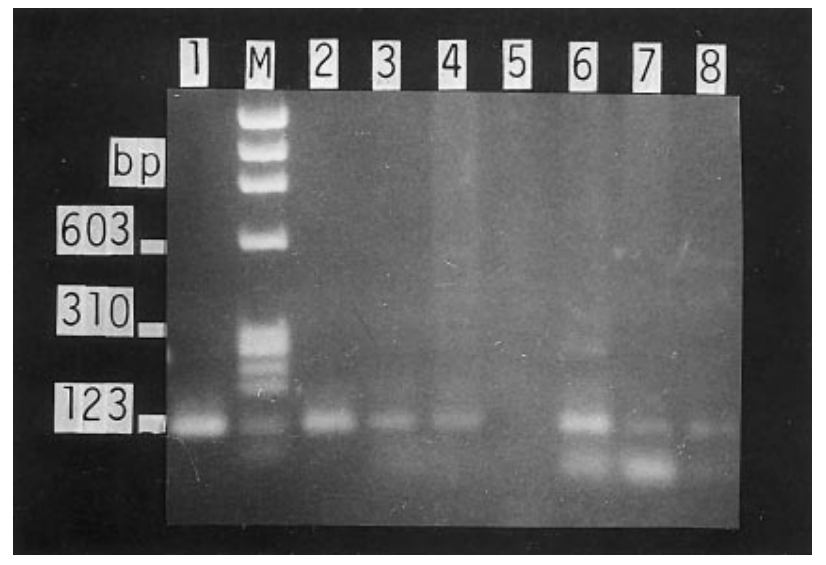

Figure 2. PCR amplification products were separated by electrophoresis on a $2 \%$ agarose gel. Lane M, HaeIII digested phage X\$174 DNA as molecular size markers; lane 1, $123 \mathrm{bp}$ marker; lane 2, positive control $\left(10^{3}\right.$ microorganisms $/ \mathrm{mL}$, from a culture of Mycobacterium tuberculosis); lanes 3 and 4, DNA from the lesion; lane 5, negative control (reaction mixture without DNA); lanes (6-8) belong to DNAs of different sputum samples from patients in whom the diagnosis of pulmonary tuberculosis is highly likely.

In addition, a positive Mantoux reaction is usually not helpful in making the diagnosis, since BCG vaccination is the rule in Turkey.

PCR technology has been used to detect $M$. tuberculosis DNA from different kinds of cutaneous tuberculosis, including lupus vulgaris, ${ }^{4-6}$ scrofuloderma, ${ }^{6,7}$ orificial tuberculosis, ${ }^{6}$ primary inoculation tuberculosis ${ }^{6}$ and disseminated tuberculosis. ${ }^{6}$ M. tuberculosis complex DNA was also found by PCR in lesions of papulonecrotic tuberculid ${ }^{8}$ and EIB. ${ }^{8-10}$

PCR is a powerful method for making or confirming the diagnosis of cutaneous tuberculosis and determining the tuberculous origin of tuberculids. We believe that the presence of relevant clinicopathological findings and a positive Mantoux reaction should not be sufficient to start antituberculosis chemotherapy, especially in countries where this reaction does not have a great value. We suggest that the tuberculous origin of tuberculids be confirmed by using PCR in order to start appropriate treatment early and avoid the improper use of complex and potentially toxic drug regimens.

\section{Acknowledgments}

The authors wish to thank Dr Namik Ozbek and Gultekin Erdogan for their help in the preparation of this correspondence.

\author{
Departments of Dermatology, \\ *Biochemistry, $†$ Pathology and \\ †Orthopaedics, \\ Baskent University School of Medicine, \\ 12. sokak $7 / 5$, \\ 06490 Bahcelievler, \\ Ankara, Turkey
}

\section{References}

1 Tappeiner G, Wolff K. Tuberculosis and other mycobacterial infections. In: Dermatology in General Medicine (Fitzpatrick TB, Eisen AZ, Wolff $\mathrm{K}$ et al., eds), 4th edn, Vol. 2. New York: McGraw-Hill, 1993; 2370-95.

2 Eisenach KD, Cave MD, Bates JH, Crawford JT. Polymerase chain reaction amplification of a repetitive DNA sequence specific for Mycobacterium tuberculosis. I Infect Dis 1990; 161: 977-81.

3 Cho K, Lee D, Kim C. Erythema induratum of Bazin. Int J Dermatol 1996; 35: 802-8.

4 Seckin D, Akpolat T, Ceyhan M et al. Polymerase chain reaction in cutaneous tuberculosis. Int J Dermatol 1997; 36: 51-4.

5 Steidl M, Neubert U, Volkenandt M et al. Lupus vulgaris confirmed by polymerase chain reaction. Br J Dermatol 1993; 129: 314-18.

6 Margall N, Baselga E, Coll P et al. Detection of Mycobacterium tuberculosis complex DNA by the polymerase chain reaction for rapid diagnosis of cutaneous tuberculosis. Br J Dermatol 1996; 135: $231-6$.

7 Taniguchi S, Chanoki M, Hamada T. Scrofuloderma: the DNA analysis of mycobacteria by the polymerase chain reaction. Arch Dermatol 1993; 129: 1618-19.

8 Degitz K, Steidl M, Thomas P et al. Aetiology of tuberculids. Lancet 1993; 341: 239-40.

9 Degitz K, Messer G, Schirren H et al. Successful treatment of erythema induratum of Bazin following rapid PCR-based detection of mycobacterial DNA. Arch Dermatol 1993; 129: 1619-20.

10 Baselga E, Margall N, Barnadas MA et al. Detection of Mycobacterium tuberculosis DNA in lobular granulomatous panniculitis (erythema induratum-nodular vasculitis). Arch Dermatol 1997; 133: 457-62.

Immunohistochemical localization of granzyme B in peritumoral infiltrates of basal cell carcinoma

SIR, Basal cell carcinomas (BCCs) are frequently associated with a peritumoral mononuclear cell infiltrate that may represent a specific antitumour response. ${ }^{1,2}$ The infiltrate largely consists of $\mathrm{T}$ cells with a predominance of the $\mathrm{CD} 4^{+} /$ $\mathrm{T}^{-}$helper over the $\mathrm{CD} 8^{+} / \mathrm{T}$-cytotoxic (Tc) subset, together with small numbers of natural killer (NK) cells. ${ }^{3}$

Several studies have shown expression of activation markers on $30-50 \%$ of $\mathrm{T}$ cells in BCC. ${ }^{4,5}$ Regression of BCC, either spontaneously or after local immunotherapy, correlates with increased numbers and activation state of peritumoral T cells, whereas aggressive tumour behaviour is associated with decreased numbers of T cells in peritumoral areas. ${ }^{6}$ Although these data suggest a cell-mediated antitumour response, the role of cells with cytolytic potential, i.e. Tc and NK cells, in immune surveillance of BCC, is not clear. The presence of characteristic granules in the cytoplasm of Tc cells and NK cells correlates with activation and subsequent cytolytic potential of these cells in vitro. These cytoplasmic granules contain a pore-forming protein, perforin, and several homologous serine proteinases called granzymes. The action of granzymes results in the apoptotic death of the target cell. ${ }^{7-10}$

Our objective was to study the expression of granzyme $\mathrm{B}$ (grB) by cells present in immune infiltrates surrounding $\mathrm{BCC}$, as an indicator of cytolytic activity against the tumour. 
Figure 1. (a) Basal cell carcinoma, single-colour stained for granzyme B (grB). The peritumoral infiltrate does not show significant grB expression. Some grB-positive cells are observed inside or close to capillaries $(\times 200)$. (b) Squamous cell carcinoma, single-colour staining for grB shows a significant number of grB-positive cells close to the tumour islands $(\times 200)$.
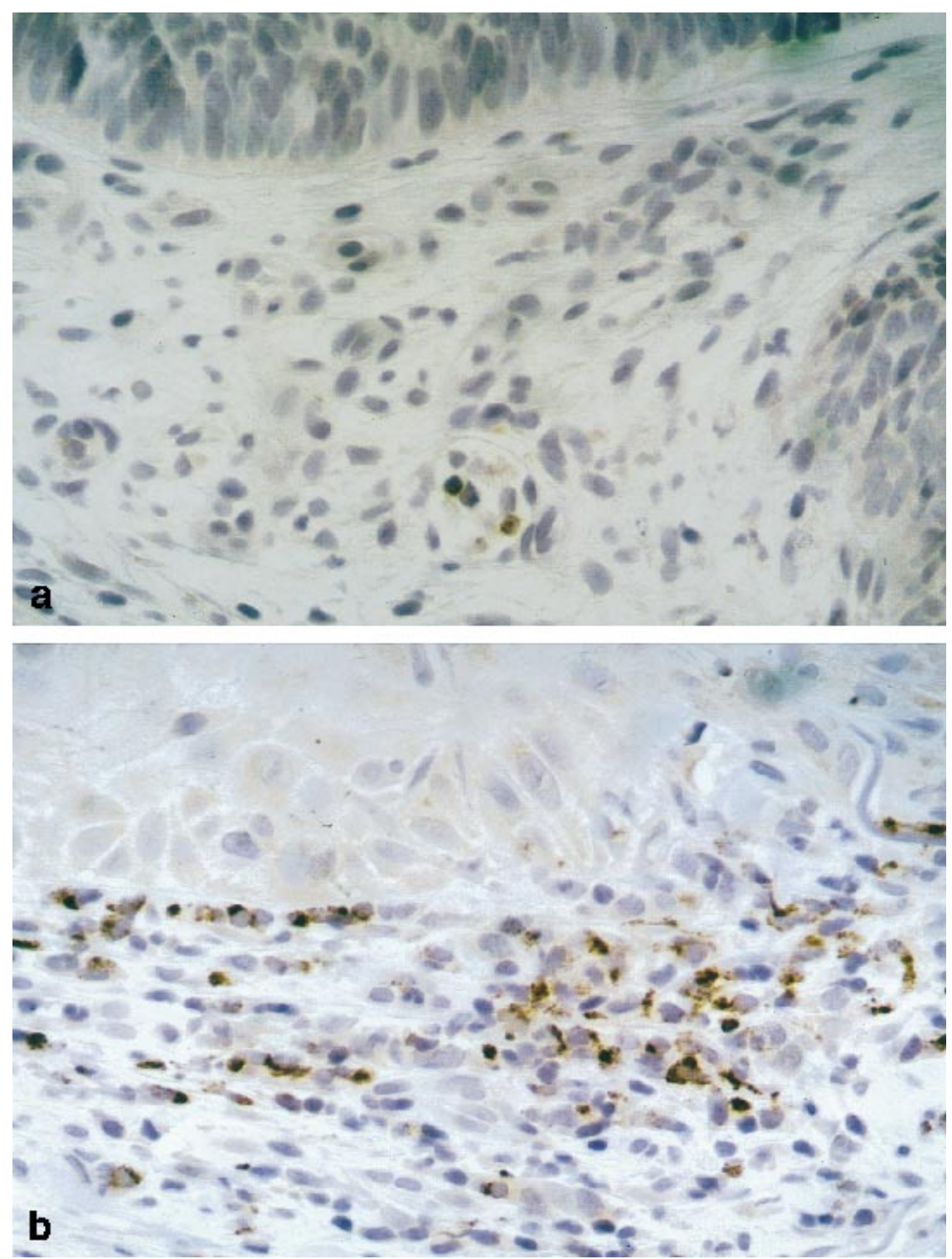

On formalin-fixed, paraffin-embedded specimens, we investigated the expression of grB in 10 patients with BCC, of whom eight were untreated and two had been treated once with intralesional interferon (IFN)- $\alpha 2 b$. Single- and two-colour staining with anti-CD3 or anti-CD8 antibodies was performed to identify the phenotype of grB-positive cells. Cells displaying a strong cytoplasmic granular staining were considered grBpositive. Immune infiltrates of BCC were compared with those of squamous cell carcinoma (SCC, $n=5)$, melanoma $(n=4)$ and inflamed seborrhoeic keratosis (SK, $n=3$ ).

Despite the presence of large numbers of CD $3+$ and CD $8+T$ cells, there was an almost striking absence of grB-positive cells in peritumoral BCC areas (Fig. 1a). The limited number of cells that expressed grB did not co-express $\mathrm{CD} 3$ or $\mathrm{CD} 8$ and consequently represented NK cells. GrB-positive NK cells were scattered mainly throughout the peritumoral stroma, but did not infiltrate the tumour lobules. Larger numbers of grBpositive NK cells as well as sporadic grB-positive Tc cells were present inside or close to capillary lumina, distant from the tumour islands. In the two cases of BCC treated with IFN$\alpha 2 \mathrm{~b} 48 \mathrm{~h}$ prior to resection, the number of grB-positive NK cells in perivascular areas appeared to be increased. In contrast with BCC, SCC, SK and melanoma showed significant numbers of grB-positive NK cells not only 'crowding' directly adjacent to the tumour, but also invading tumour islands (Fig. $1 \mathrm{~b})$. The number of grB-positive Tc cells in these conditions was small, although increased compared with BCC.

In this study, we investigated the possible role of Tc cells and NK cells as active participants in immune surveillance towards BCC, by analysis of grB expression. The majority of 
peritumoral Tc cells did not express grB, while only a limited number of grB-positive NK cells was present. The expression of $\mathrm{grB}$ can be used as a specific, functional marker for activated Tc cells in vivo, i.e. grB characterizes a specific Tcell population that has been stimulated by recognition of its target. These T cells possess lytic potential. We conclude that in patients with $\mathrm{BCC}$, the 'activated' state of peritumoral $\mathrm{T}$ cells apparently does not lead to expression of granzymes and subsequent cytolytic activity by cytotoxic $\mathrm{T}$ cells present in these infiltrates.

\section{Acknowledgements}

Monoclonal antibody GrB7 was a kind gift of Prof. C.E.Hack from the Central Laboratory of the Netherlands Red Cross Blood Transfusion Service in Amsterdam.

Department of Dermatology,

University Hospital Maastricht,

Maastricht, The Netherlands

*Renal Transplant Unit AMC,

University of Amsterdam,

Amsterdam, The Netherlands

\section{References}

1 Curson C, Weedon D. Spontaneous regression in basal cell carcinomas. J Cutan Pathol 1979; 6: 432-7.

2 Hunt MJ, Halliday GM, Weedon D et al. Regression in basal cell carcinoma: an immunohistochemical analysis. $\mathrm{Br} J$ Dermatol 1994; 130: $1-8$.

3 Habets JM, Tank B, Vuzevski VD et al. Characterization of the mononuclear infiltrate in basal cell carcinoma: a predominantly $\mathrm{T}$ cell-mediated immune response with minor participation of Leu$7^{+}$(natural killer) cells and Leu- $14^{+}$(B) cells. J Invest Dermatol 1988; 90: 289-92.

4 Guillén FJ, Day CL, Murphy GF. Expression of activation antigens by T cells infiltrating basal cell carcinomas. J Invest Dermatol 1985; 85: 203-6.

5 Markey AC, Churchill LJ, Allen MH et al. Activation and inducer subset phenotype of the lymphocytic infiltrate around epidermally derived tumors. J Am Acad Dermatol 1990; 23: 214-20.

6 Deng JS, Brod BA, Saito R, Tharp MD. Immune-associated cells in basal cell carcinomas of skin. J Cutan Pathol 1996; 23: 140-6.

7 Kummer JA, Kamp AM, Tadema TM et al. Localization and identification of granzymes A and B-expressing cells in normal human lymphoid tissue and peripheral blood. Clin Exp Immunol 1995; 100: 164-72.

8 Griffiths GM, Mueller C. Expression of perforin and granzymes in vivo: potential diagnostic markers for activated cytotoxic cells. Immunol Today 1991; 12: 415-19.

9 Kummer JA, Kamp AM, van Katwijk M et al. Production and characterization of monoclonal antibodies raised against recombinant human granzymes $\mathrm{A}$ and $\mathrm{B}$ and showing cross reactions with natural proteins. J Immunol Methods 1993; 163: $77-83$.

10 Shresta S, Heusel JW, Macivor DM et al. Granzyme B plays a critical role in cytotoxic lymphocyte-induced apoptosis. Immunol Rev 1995; 146: 211-21.
Histidinohydroxylysinonorleucine, a trifunctional cross-link of type I collagen, in sun-exposed and sun-protected human skin

SIR, Histidinohydroxylysinonorleucine (HHL), a non-reducible trifunctional collagen cross-link derived only from type I collagen in mature bovine or human skin, was recently identified. ${ }^{1,2}$ This stable intermolecular cross-link that binds three amino acid residues of two collagen $\alpha 1$ (I) chains and one collagen $\alpha 2(\mathrm{I})$ chain, is assumed to provide collagen fibres with their stability and physiochemical properties. ${ }^{3}$ A conventional method using amino acid analysis has been carried out for the HHL measurement in human skin. ${ }^{3,4}$ This method, however, is time-consuming and requires a large amount of skin. We have developed a novel high-performance liquid chromatography (HPLC) system which enables the measurement of the HHL content in small samples at a picomole order. $^{5}$

A 6-mm punch biopsied skin sample was obtained from six healthy volunteers over 70 years of age. Approximately $1 \mathrm{mg}$ of lyophilized dermis was hydrolysed after pulverization. Twenty-five microlitres of the skin hydrolysate, diluted in borate buffer (amino acid concentration: $0.25 \mathrm{mmol} / \mathrm{L}$ ), $25 \mu \mathrm{L}$ of $3 \mathrm{mmol} / \mathrm{L} N^{\varepsilon}$-methyl-L-lysine-HCl as an internal standard, $25 \mu \mathrm{L}$ of water and $50 \mu \mathrm{L}$ of acetone, were mixed, and $6 \mathrm{mmol} / \mathrm{L}$ 9-fluorenylmethyl chloroformate (FMOC-Cl) in acetone was added at room temperature. After extraction with pentane, the aqueous phase was subjected to HPLC using Inertsil ODS-2 stainless steel column $(4 \cdot 5 \times 150 \mathrm{~mm}$, GL Sciences, Tokyo, Japan). FMOC-Cl derivatives were detected fluorescently. A gradient elution system with 40 or $60 \%$ acetonitrile in $0.3 \%$ acetic acid buffer containing $0.08 \mathrm{mmol} / \mathrm{L} \mathrm{NaCl}(\mathrm{pH} \mathrm{4.7)}$ was employed. Hydroxyproline was also determined by HPLC, according to the previous method. ${ }^{6}$

The peak of HHL was clearly detected and linearity for HHL referred to an internal standard was confirmed from 1 to $10 \mathrm{pmol}$. The HHL content was expressed as a molar ratio to collagen $(\mathrm{mol} / \mathrm{mol})$ calculated on the basis of 300 residues of hydroxyproline in one collagen molecule. As shown in Table 1 , the HHL content in the sun-exposed site $(0 \cdot 29 \pm$ $0 \cdot 05$; mean $\pm \mathrm{SD}$ ) was significantly decreased in comparison

Table 1. HHL content in sun-exposed and sun-protected sites as measured by HPLC

\begin{tabular}{|c|c|c|c|}
\hline \multirow[b]{2}{*}{ No. } & \multirow[b]{2}{*}{ Age/sex } & \multicolumn{2}{|c|}{ Ratio of HHL/collagen $(\mathrm{mol} / \mathrm{mol})$} \\
\hline & & Sun-exposed site & Sun-protected sit \\
\hline 1 & $70 / \mathrm{M}$ & $0 \cdot 33$ (wrist) & 0.56 (buttock) \\
\hline 2 & $72 / \mathrm{M}$ & $0 \cdot 26$ (wrist) & 0.61 (buttock) \\
\hline 3 & $70 / \mathrm{M}$ & $0 \cdot 28$ (wrist) & 0.46 (buttock) \\
\hline 4 & $75 / \mathrm{M}$ & $0 \cdot 22$ (dorsum of hand) & $0 \cdot 37$ (groin) \\
\hline 5 & $70 / \mathrm{M}$ & $0 \cdot 34$ (wrist) & $\mathrm{ND}^{*}$ \\
\hline 6 & $70 / \mathrm{F}$ & $\mathrm{ND}^{*}$ & 0.50 (back) \\
\hline \multicolumn{2}{|c|}{ Mean \pm SD } & $0 \cdot 29 \pm 0.05 \dagger$ & $0.50 \pm 0.09$ \\
\hline
\end{tabular}

*ND, not determined; $\uparrow P<0 \cdot 002$. 
with that of the sun-protected site $(0.50 \pm 0.09)(P<0.002$ by Student's $t$-test).

It has been demonstrated that the amount of HHL gradually increases from birth to the fifth decade of life, presumably reflecting skin maturity, ${ }^{3}$ and decreases in sun-exposed skin when compared with sun-protected skin. ${ }^{4}$ Inflammatory cells in ultraviolet-irritated skin were assumed to hydrolyse collagen enzymatically. ${ }^{7}$ In this context, ultraviolet B irradiation induces the production of tumour necrosis factor- $\alpha$ (TNF- $\alpha$ ) by keratinocytes, ${ }^{8}$ and then TNF- $\alpha$ stimulates collagenase activity $^{9}$ and inhibits collagen gene transcription by fibroblasts. ${ }^{10}$ These observations suggest that collagen degradation in the skin may be accelerated by ultraviolet irradiation (e.g. photolysis and impediment of HHL formation). However, in vitro experiments revealed that the HHL structure itself was resistant to ultraviolet A or B irradiation. ${ }^{4}$ Therefore, it is conceivable that the decreased amount of HHL in sun-exposed skin is indirectly caused by the degradation of collagen peptides other than HHL. Alternatively, there may be a site difference rather than a difference due to photodamage. Our preliminary data on the HHL content in swine skin suggested that site difference is the explanation (data not shown).

The measurement of HHL content with high sensitivity is an absolute requirement when investigating the metabolism of HHL in vivo and in vitro. The present study clearly indicates that our novel method is applicable to this purpose and is promising for use in future studies of cutaneous ageing for the measurement of collagen cross-links.

Department of Dermatology, Gunma University School of Medicine, Maebashi 371, Japan

E-mail:kokada@sb.gunma-u.ac.jp
K.ОKADA

A.KONDO

O.ISHIKAWA Y.MIYACHI

\section{References}

1 Mechanic GL, Katz EP, Henmi M et al. Locus of a histidine-based stable trifunctional, helix to helix collagen cross-link: stereospecific collagen structure of type I skin fibrils. Biochemistry 1987;; 26: 3500-9.

2 Yamauchi M, London RE, Guenat C et al. Structure and formation of a stable histidine-based trifunctional cross-link in skin collagen. J Biol Chem 1987; 262: 11428-34.

3 Yamauchi M, Woodley DT, Mechanic GL. Aging and cross-linking of skin collagen. Biochem Biophys Res Commun 1988; 152: 898-903.

4 Yamauchi M, Prisayanh P, Haque Z, Woodley DT. Collagen crosslinking in sun-exposed and unexposed sites of aged human skin. J Invest Dermatol 1991; 97: 938-41.

5 Kondo A, Ishikawa O, Okada K et al. Measurement of histidinohydroxylysinonorleucine and hydroxyproline in skin collagen by reversed phase HPLC after 9-fluorenylmethyl chloroformate labeling. Anal Biochem (in press).

6 Einarsson S. Selective determination of secondary amino acids using precolumn derivatization with 9-fluorenylmethylchloroformate and reversed-phase high-performance liquid chromatography. J Chromatogr 1985; 348: 213-20.

7 Kligman LH, Gebre M, Alper R, Kefalides NA. Collagen metabolism in ultraviolet irradiated hairless mouse skin and its correlation to histochemical observations. J Invest Dermatol 1989; 93: 210-14.

8 Köck A, Schwarz T, Kirnbauer R et al. Human keratinocytes are a source for tumor necrosis factor alpha. Evidence for synthesis and release upon stimulation with endotoxin or ultraviolet light. J Exp Med 1990; 172: 1609-14.

9 Dayer J-M, Beutler B, Cerami A. Cachectin/tumor necrosis factor stimulates collagenase and prostaglandin $\mathrm{E}_{2}$ production by human synovial cells and dermal fibroblasts. J Exp Med 1985; 162: 2163-8.

10 Solis-Herruzo JA, Brenner DA, Chojkier M. Tumor necrosis factor $\alpha$ inhibits collagen gene transcription and collagen synthesis in cultured human fibroblasts. J Biol Chem 1988; 263: 5841-5.

\section{Computed tomography reveals thickened subcutaneous tissue in scleroedema}

SIR, Scleroedema adultorum is a connective tissue disease of unknown aetiology, which is clinically characterized by diffuse, non-pitting oedema and induration of the skin. A thickened dermis with large spaces between collagen bundles has been well known as the pathological hallmark of this disease. ${ }^{1}$ Although it is suggested that the subcutaneous tissue is involved, ${ }^{2}$ no morphological evidence has been demonstrated. We recently examined the involved skin of six scleroedema patients by computed tomography (CT), and found that the subcutaneous tissue was significantly increased in thickness.

We studied six patients with scleroedema (four men and two women, mean \pm SD age $48 \cdot 2 \pm 14 \cdot 8$ years) and 35 control
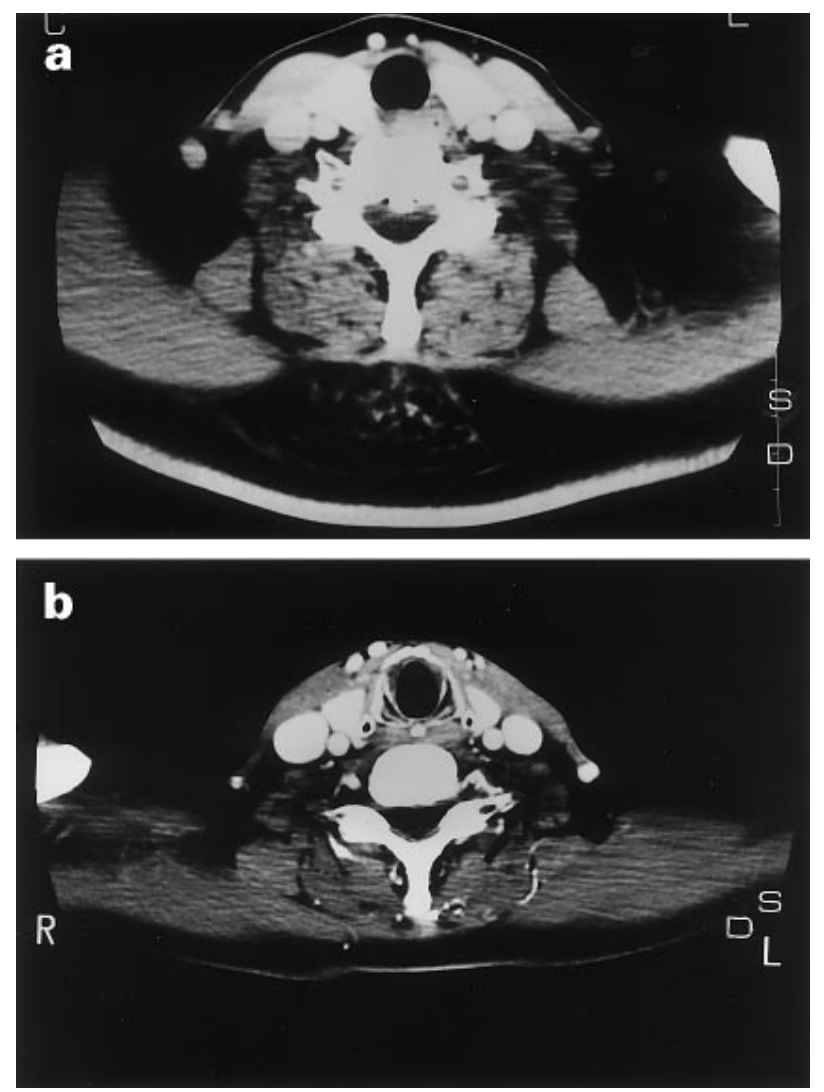

Figure 1. The CT image of a scleroedema patient (a) and of a normal control (b). The dermis (D) and subcutaneous fatty tissue (S) of the former are thicker than the latter. R, right; L, left. 
Table 1. Summary of clinical features of patients with scleredema and contol patients

\begin{tabular}{|c|c|c|c|c|}
\hline & $\begin{array}{c}\text { Age } \\
(\text { years }) \\
\text { mean } \pm \text { SD }\end{array}$ & $\begin{array}{l}\text { Body mass } \\
\text { index }{ }^{1} \\
\text { mean } \pm \mathrm{SD}\end{array}$ & $\begin{array}{c}\text { Thickness of } \\
\text { subcutaneous } \\
\text { tissue }(\mathrm{mm}) \\
\text { mean } \pm \mathrm{SD}\end{array}$ & $\begin{array}{l}\text { Thickness of } \\
\text { dermis }(\mathrm{mm}) \\
\text { mean } \pm \mathrm{SD}\end{array}$ \\
\hline Patients & $48 \cdot 2 \pm 14 \cdot 8$ & $26 \cdot 9 \pm 2 \cdot 70$ & $28 \cdot 8 \pm 8 \cdot 91$ & $7 \cdot 95 \pm 1 \cdot 30$ \\
\hline Obese controls & $62 \cdot 0 \pm 15 \cdot 3$ & $28 \cdot 6 \pm 0 \cdot 90$ & $16 \cdot 3 \pm 6 \cdot 56$ & $2.51 \pm 0.65^{2}$ \\
\hline Normal controls & $56 \cdot 9 \pm 13 \cdot 7$ & $20 \cdot 9 \pm 7 \cdot 01$ & $15 \cdot 7 \pm 7 \cdot 94$ & \\
\hline
\end{tabular}

${ }^{1}$ Body mass index is calculated by weight $(\mathrm{kg}) /$ height $^{2}(\mathrm{~m})$

${ }^{2}$ These controls are from other CT studies.

patients with non-dermatological diseases (18 men and 17 women, mean \pm SD age $56 \cdot 9 \pm 13 \cdot 7$ years) (Table 1 ). Diabetes mellitus was present in five scleroedema patients, and was of the non-insulin-dependent type in four. When the body mass index (BMI) was calculated as weight $(\mathrm{kg}) /\left(\right.$ height $\left.^{2}(\mathrm{~m})\right)$, it was found to be at least 25 in all scleroedema patients. The control patients were divided into nine patients who had BMI of more than 25 (abbreviated as $>25$ obese controls) and 26 who had a BMI of less than 25 (abbreviated as 25 obese controls). By using CT, the thickness of the dermis and subcutaneous tissue was determined at the level of the seventh cervical vertebra. A comparison was made between the scleroedema and the control patients (Fig. 1), using the Mann-Whitney test.

In the CT images, the mean thickness $( \pm \mathrm{SD})$ of subcutaneous tissue was $28.8 \pm 8.91 \mathrm{~mm}$ in the six scleroedema patients and $16.3 \pm 6.56 \mathrm{~mm}$ in BMI $>25$ obese controls. The former was significantly greater than the latter $(p=0 \cdot 006)$. The average BMI was not significantly different between scleroedema patients $(26 \cdot 9 \pm 2 \cdot 70)$ and the BMI $>25$ obese controls $(28 \cdot 6 \pm 0 \cdot 90, P=0 \cdot 182)$. Furthermore, the thickness of subcutaneous tissue did not significantly differ between the BMI $>25$ obese controls $(16 \cdot 3 \pm 6.56 \mathrm{~mm})$ and BMI 25 obese controls $(15 \cdot 7 \pm 7 \cdot 94 \mathrm{~mm} P=0 \cdot 317)$. When the dermis was measured by $\mathrm{CT}$, the mean $( \pm \mathrm{SD})$ thickness was $7.95 \pm 1.70 \mathrm{~mm}$ in the scleroedema patients and $2.51 \pm 0.65 \mathrm{~mm}$ in the controls. The former was significantly thicker than the latter $(P<0 \cdot 001)$.

Our study has demonstrated that the subcutaneous tissue was significantly thicker in the involved areas of scleroedema compared with the normal-appearing skin of obese controls. As the thickness of the subcutaneous tissue was not significantly different between obese and non-obese controls, the thickening is likely to be a specific finding in scleroedema adultorum. Our CT study also demonstrated that the dermis is much thicker in scleroedema patients than in controls. The thickened dermis has been confirmed histologically ${ }^{3}$ and in terms of image analysis using ultrasound scan. ${ }^{4}$ The skin in scleroedema adultorum is often slightly elevated and swollen, ${ }^{5}$ a clinical feature that may be associated with thickened subcutaneous tissue.

Fibrotic skin fibroblasts from a non-diabetic scleroedema patient have been demonstrated to show an increase in total collagen synthesis and in type I collagen mRNA, and to show enhanced collagen production and elevated type I procollagen mRNA in a diabetic scleroedema patient. ${ }^{6}$ The thickening of the subcutaneous tissue may be explained by increased collagen and mucin deposition in the septum. Furthermore, in scleroedema associated with noninsulin-dependent diabetes, the increased amount of insulin may stimulate the nuchal fibroblasts and pre-adipocytes and thereby increase the quantity of collagen fibres and adipose cells. ${ }^{7}$ In our study, five patients had diabetes of whom four were non-insulin-dependent. A recent report has demonstrated that glucose intolerance had greater influence on the upper body segment than on the lower body segment. ${ }^{8}$ Such a finding is consistent with the evidence that the subcutaneous tissue is usually thickened in the upper body segment in diabetic scleroedema.

Department of Dermatology,

K.MATSUURA University of Tsukuba,

Ten-nodai 1-1-1,

Ibaraki 305, Japan

\section{References}

1 Varga J, Gotta S, Li L et al. Scleroedema adultorum: case report and demonstration of abnormal expression of extracellular matrix genes in skin fibroblasts in vivo and in vitro. Br J Dermatol 1995; 132: 992-9.

2 UItto J. Jiminez S. Fibrotic skin disease: clinical presentations, etiologic considerations and treatment options. Arch Dermatol 1990; 126: 661-4.

3 Cole HG, Winkelmann RK. Acid mucopolysaccharide staining in scleroedema. J Cutan Pathol 1990; 17: 211-13.

4 Cole GW, Handler SJ, Burnett K. The ultrasonic evaluation of skin thickness in scleredema. J Clin Ultrasound 1981; 9: 501-3.

$5 \mathrm{Ohm} \mathrm{A}$, Uitto J, Oikarinen A et al. Paraproteinemia in patients with scleredema: clinical findings and serum effects on skin fibroblasts in vitro. J Am Acad Dermatol 1987; 16: 96-107.

6 Oikarinen A, Ala-Kokko L, Palatsi $\mathrm{R}$ et al. Scleredema and paraproteinemia. Arch Dermatol 1987; 123: 226-9.

7 Krieger Brauer HI, Kather H. Human fat cells possess a plasma membrane-bound $\mathrm{H}_{2} \mathrm{O}_{2}$-gentrating system that is activated by insulin via a mechanism bypassing the receptor kinase. J Clin Invest 1992; 89: 1006-13.

8 Rice T, Province M. Cross-trait familial resemblance for body fat and blood pressure: familial correlations in the Quebec family study. Am J Hum Genet 1994; 55: 1019-29. 


\section{Lamellar ichthyosis is markedly improved by a noval} combination of emollients

SIR, Lamellar ichthyosis (LI) is a rare, congenital genodermatosis characterized by generalized hyperkeratosis, intense dryness of the skin, and large scales especially over the extremities. ${ }^{1}$ Although usually not life threatening, the disease can be very disfiguring and causes considerable distress to sufferers throughout life. The treatment of LI involves the use of oral vitamin A derivatives (retinoids) and various topical emollients such as urea, propylene glycol and alpha-hydroxy acids (AHA). Unfortunately, the therapeutic results are often meagre and associated with side-effects. In trying to improve therapy, one of us (A.G.), by serendipity, noted in her own children suffering from LI, that a mixture of $5 \%$ lactic acid and $20 \%$ propylene glycol in a commercially available cream base (Locobase $^{\circledR}$, Lipobase ${ }^{\circledR}$, Yamanouchi, The Netherlands) was clearly superior to previously used emollients. Since a search in the literature revealed no data on an identical formulation, we conducted the following open study.

Ten patients (seven women, three men; age 2-38 years) with severe LI (two of whom had ongoing treatment with oral acitretin, $50-75 \mathrm{mg} /$ day) were recruited after informed consent. Instead of applying their ordinary creams containing 5$10 \%$ urea or $3-10 \%$ lactic acid, the patients were instructed to apply the new formulation (see above) twice daily to the legs. Signs of scaling, hyperkeratosis and xerosis were separately scored (0-4) and the sums of scores (maximum: 12) were calculated for each patient before and after changing therapy. The use of the new formulation resulted, after 1 month, in a reduction of the mean $(\mathrm{SD})$ total score from $9.6(2 \cdot 2)$ to 3.5 $(2 \cdot 3)(P<0 \cdot 001$; paired $t$-test). All patients reported increased shedding of scales after a few days' treatment, followed within
1-2 weeks by the appearance of a much smoother, almost normal-looking skin (Fig. 1). Nine patients considered the effect 'better than ever obtained before', and later chose to extend the treatment to the rest of the body with equally good results. One patient was able to reduce her acitretin dosage from 75 to $25 \mathrm{mg}$ daily without deterioration of skin symptoms. Although some patients experienced a transient skin irritation after applying the cream, only one patient stopped therapy because of this. No other side-effects were noted.

van Scott and Yu pioneered the use of AHA for ichthyotic conditions. $^{2}$ They also described a keratolytic gel $(5-10 \%$ AHA in water, ethanol and propylene glycol-4:4:2), ${ }^{3}$ the use of which fell into oblivion as it was irritating and unsuitable for whole body application. A better-tolerated, although still somewhat irritating formulation, is Lac-Hydrin ${ }^{\circledR}$ cream (Westwood-Squibb Pharm. Inc., Buffalo, NY, U.S.A.) containing $12 \%$ ammonium lactate in a propylene glycol-containing base. The combination of only 5\% lactic acid and 20\% propylene glycol in a lipophilic cream base (Locobase ${ }^{\circledR}$, Lipobase $^{\circledR}$ ) is, in our experience, readily accepted by most patients and much more effective, and less irritating than monotherapy with either compound at twice these concentrations. The potent effect of this mixture suggests that the ingredients act synergistically in reverting hyperkeratosis. How this relates to the pathogenesis of LI is unclear. One recently detected cause of $\mathrm{LI}$ is deficiency of epidermal transglutaminase, a cross-linking enzyme essential for the formation of cornified cell envelopes. ${ }^{4}$ Hypothetically, lactic acid, which reduces ambient $\mathrm{pH}$, hydrates keratins and dissociates cells in the lower stratum corneum, ${ }^{3}$ and propylene glycol, which dissolves other compounds, increases skin penetration and detaches corneocytes from the skin surface, ${ }^{5}$ might cooperatively stimulate remaining enzyme activities and restore
Figure 1. A 12-year-old boy with lamellar ichthyosis due to transglutaminase deficiency, showing (a) the situation before and (b) after 1 month of switching from $5 \%$ lactic acid in Locobase ${ }^{\circledR}$ to $5 \%$ lactic acid and 20\% propylene glycol in Locobase ${ }^{\circledR}$ twice daily.
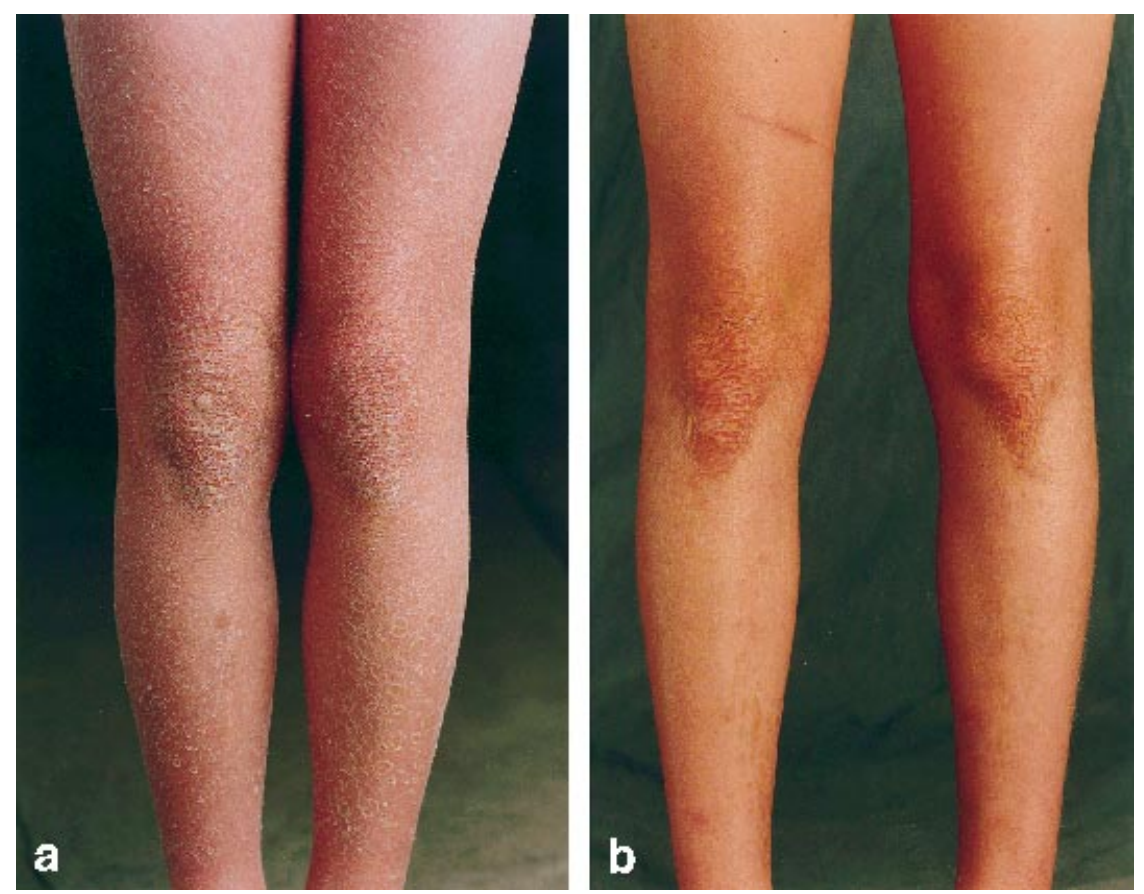
a more normal skin desquamation (for a review see Rawlings et al.). ${ }^{6}$ In an ongoing clinical trial, we are trying to establish the optimal composition of a lactic acid/propylene glycolcontaining lipophilic cream for use in different ichthyotic conditions, and are attempting to elucidate its mechanism of action.

\section{Department of Dermatology,}

A.GNEmo University Hospital,

75185 Uppsala, Sweden

A.VAHLQUIST

\section{References}

1 Traupe H (ed.) The Ichthyoses. A Guide to Clinical Diagnosis, Genetic Counselling, and Therapy. Berlin: Springer-Verlag, 1989.

2 van Scott EJ, Yu RJ. Control of keratinization with alfa-hydroxy acids and related compounds. Arch Dermatol 1974; 110: 586-90.

3 van Scott EJ, Yu RJ. Hyperkeratinization, corneocyte cohesion, and alfa-hydroxy acids. J Am Acad Dermatol 1984; 11: 867-79.

4 Huber M, Rettle I, Bervasconi K, et al. Mutations of keratinocyte transglutaminase in lamellar ichthyosis. Science 1995; 267: 525-8.

5 Goldsmith LA. Propylene glycol. Int J Dermatol 1978; 17: 703-5.

6 Rawlings AV, Scott IR, Harding AR, Bowser PA. Stratum corneum moisturization at the molecular level. J Invest Dermatol 1994; 103: 731-40.

\section{Venous lakes treated by liquid nitrogen cryosurgery}

SIR, The venous lake, a 'blueberry on the lip', is a common variation of venous ectasia that occurs on the lips ${ }^{1}$ (Figs 1a and c). It is formed from a thin layer of epithelial cells and supported by a strong fibrous wall. Hence, it is not a true haemangioma, in spite of its common name of 'senile haemangioma of the lip'. ${ }^{2}$ Its importance is not limited to the cosmetic, as trauma may result in profuse bleeding. The literature on the treatment of venous lakes is limited, but includes surgical excision, electrodesiccation, cryosurgery, laser therapy ${ }^{3}$ and infra-red coagulation. ${ }^{4}$ The technique and results of cryosurgery are published but are not widely known. ${ }^{5,6}$

The use of cryosurgery for venous lakes is based on tissue selectivity. The cryoprobe technique, also known as contact therapy, is quick and relatively simple. Cryosurgery is based on the rapid cooling of tissue with liquid nitrogen. The temperature changes cause disintegration of the cell membranes. Vasoconstriction, then vasodilatation, and microthrombosis in the capillaries and arterioles lead to partial ischaemic necrosis. $^{7}$

Deep destruction of tissue, as is needed for the treatment of a malignant lesion, is not desirable. Overfreezing is avoided and a single freeze-thaw cycle is sufficient. No local anaesthetic is needed, and protection of the lip is unnecessary. The cryoprobe is placed onto the lesion, pressed against it to compress the blood within, and the lesion is frozen together with a 1$1.5 \mathrm{~mm}$ rim of normal tissue. The probe is generally precooled, so that it does not adhere to the lip. The duration of cooling (freeze time) is $5-15 \mathrm{~s}$, depending on the size of the lesion.

There is no visible damage to the tissue during or immediately after freezing. Oedema occurs after several minutes, with later bulla formation or sloughing. The patient may experience discomfort but pain is tolerable and eating or washing is not affected. Wound healing occurs after 2-3 weeks without discoloration of the lip or scarring (Figs 1a and b). In larger lesions, or after repeated treatments, some scarring may develop (Figs $1 \mathrm{c}$ and 1d) which is smooth and improves with time.

In addition to a hand-held unit containing liquid nitrogen, the most important instrument is a cryoprobe. Different sizes of round closed probes are available commercially but can also be made by a skilful technician. The contact surface consists of a thin flat copper or brass plate, $0 \cdot 2-0.3 \mathrm{~mm}$ in diameter, so that cooling is rapid and easily controlled. The probes of diameters $2-5 \mathrm{~mm}$, or $8 \mathrm{~mm}$, are best. Luer-mount probes
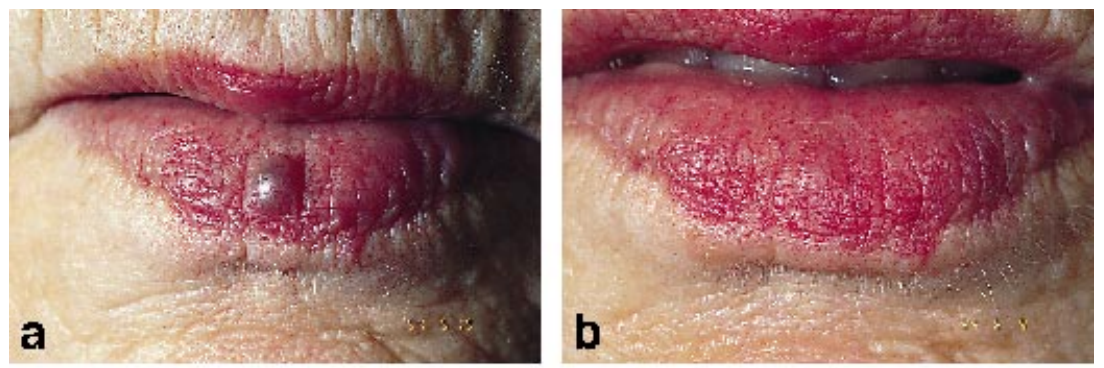

Figure 1. (a) Typical venous lake on the lower lip before cryosurgery. (b) Complete healing after 3 weeks. Note the normal colour and surface texture of the lip. (c) An unusually wide venous lake on the upper lip was treated in sections by overlapping the freezing. (d) Good functional and aesthetic results at 2 months after two treatment sessions. There is no palpable scarring.
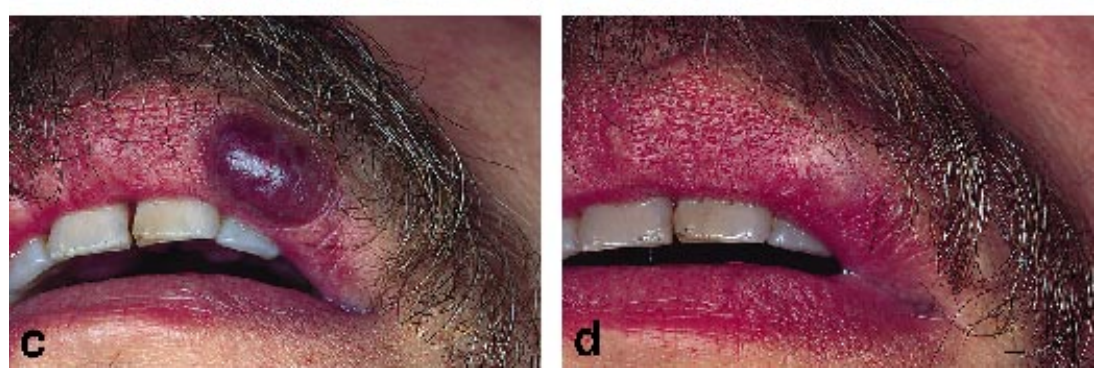
and adapters allow the use of cryosurgical devices with a nonstandard mount. When using a contact probe, one should consider it as any other contact instrument and sterilize it after each use.

Cryosurgical treatment of venous lakes is safe, yields excellent results, is inexpensive, and suitable for most patients. It should not be used for those patients with cold-induced problems. The ice front should not extend beyond the vermilion margin as this can result in scarring or some loss of pigmentation. $^{5}$

Department of Dermatology,

R.SUHONEN

Mikkeli Central Hospital, E.G.KUFLIK*

FIN 50100 Mikkeli, Finland

*University of Medicine and Dentistry,

New Jersey Medical School, Newark,

NJ, U.S.A.

\section{References}

1 Bean WEB, Walsh JR. Venous lakes. Arch Dermatol 1956; 74: 459-63.

2 Alcalay J, Sandbank M. The ultrastructure of cutaneous venous lakes. Int J Dermatol 1987; 26: 645-6.

3 Burton JL. The lips. In: Textbook of Dermatology (Champion RH, Burton JL, Ebling FJG, eds), 5th edn. Oxford: Blackwell Scientific Publications, 1992; 2772-3.

4 Colver GB, Hunter JAA. Venous lakes: treatment by infrared coagulation. Br J Plast Surg 1987; 40: 451-3.

5 Torre D, Lubritz RR, Kuflik EG. In: Practical Cutaneous Cryosurgery. Norwalk: Appleton \& Lange, 1988; 71-2.

6 Kuflik EG. Cryosurgery updated. J Am Acad Dermatol 1994; 31: 925-44.

7 Kuflik EG, Gage AA. Cryosurgical Treatment of Skin Cancer. New York: Igaku-Shoin, 1990; 35-52.

\section{Digital sympathectomy (microarteriolysis) in the treatment of severe Raynaud's phenomenon secondary to systemic sclerosis}

SIR, Raynaud's phenomenon secondary to systemic sclerosis can become incapacitating. In the largest placebo-controlled double-blind trial of iloprost, 39\% of patients experienced a decrease in Raynaud's attacks (vs. 22\% with placebo, $P=0 \cdot 005) .{ }^{1}$ These results are in accordance with the clinical experience that nifedipine $e^{2,3}$ and iloprost ${ }^{1}$ can be effective in the short-term palliation of secondary Raynaud's phenomenon but that there are many non-responders. We report on two patients with finger ulcers and intractable pain due to secondary Raynaud's phenomenon. Both patients underwent digital sympathectomy and remained free of vasospastic symptoms for more than 2 years.

A 77-year-old woman presented with severe Raynaud's phenomenon. A diagnosis of systemic sclerosis of the peripheral type was based on pathological capillaroscopy and a high titre of anticentromere antibodies. Progressive finger tip ulceration and intractable pain of the right index finger and middle finger did not respond to nifedipine $(30 \mathrm{mg} /$ day $)$ and aspirin $(100 \mathrm{mg} /$ day) nor to intravenous iloprost therapy ( $2 \mathrm{ng} / \mathrm{kg}$ per hour for $6 \mathrm{~h} /$ day for 3 weeks). Systolic pressure was below $50 \mathrm{mmHg}$ in both fingers, indicating critical ischaemia. Bilateral digital sympathectomy resulted in rapid relief of pain and recovery of digital systolic pressure.

An 82-year-old woman had had Raynaud's phenomenon since youth. Two years ago, the attacks became more frequent and painful. She presented with the CREST-syndrome. A diagnosis of systemic sclerosis of the peripheral type was confirmed by the findings of giant nail-fold capillaries and a high titre of anticentromere antibodies $(1: 5120)$. She did not respond to nifedipine and aspirin and refused intravenous iloprost because of intolerable headaches under treatment. Finally, she requested amputation of her right index finger because of intractable pain and progressive finger tip necrosis. One year later, severe vasospastic symptoms led to a comparable situation in the left index finger. Bilateral digital sympathectomy resulted in complete disappearance of pain. The finger tip necrosis healed within 4 weeks and the Raynaud's phenomenon improved substantially for more than 2 years.

Intractable pain, finger tip necrosis and finger contractures can be part of Raynaud's phenomenon secondary to systemic sclerosis. General measures include protection from cold temperature exposure and cessation of smoking. Nifedipine and prostaglandins such as iloprost are often effective in the treatment of secondary Raynaud's phenomenon, ${ }^{1-3}$ but there remain many non-responders.

After upper dorsal thoracic sympathectomy (ganglia $\mathrm{T}_{2}-$ $\mathrm{T}_{4}$ ), most patients have initial improvement of Raynaud's phenomenon, but a relapse almost always occurs 6 months after the operation. ${ }^{4,5}$ During the last 10 years, thoracoscopic upper dorsal sympathectomy has rapidly gained ground in the treatment of palmar hyperhidrosis. ${ }^{6}$ For unknown reasons, the long-term results for primary hyperhidrosis of the palms are excellent, ${ }^{7}$ whereas long-term results for secondary Raynaud's phenomenon are less consistent. Claes et al. observed that patients with sympathectomy due to hand sweat experienced warm hands for 6 months. After this period the temperature normalized without recurrence of hyperhidrosis. ${ }^{5,7}$ Flatt and others ${ }^{8-10}$ hypothesized that relapses were probably due to sympathic reinnervation of the brachial plexus (C4-Thl) via communicating nerve fibres.

For this reason, Flatt introduced the technique of digital artery sympathectomy. ${ }^{8}$ The adventitia of the digital arteries is surgically removed over a length of $4 \mathrm{~mm}$. Eight patients with digital vascular insufficiency from different causes experienced symptomatic relief after this procedure. ${ }^{8}$ Electron microscopy confirmed that unmyelinated axons were present in the adventitia removed. Wilgis extended the procedure to a length of $2 \mathrm{~cm}$ and reported pain relief and ulcer healing in eight of nine patients. ${ }^{9}$ O'Brien et al. reported pain relief and ulcer healing in all of 11 patients with systemic sclerosis. ${ }^{10}$ They removed the adventitia of all palmar arteries (radical microarteriolysis) including the distal ulnar artery, superficial palmar arch and the digital arteries. If the ulnar artery were occluded, a venous bypass was inserted. In contrast to thoracic sympathectomy no (or only minor) recurrences of Raynaud's phenomenon are seen after digital sympathectomy. ${ }^{8-10}$ Kaarela et al. investigated digital sympathectomy in monkeys. They showed that adrenergic nerves distal to the site of the 
operation remained normal after removal of the adventitia, and hypothesized that the removal of the thickened adventitia from the vasospastic arteries was mainly responsible for the positive effect. ${ }^{11}$ For this reason, O'Brien et al. suggested that the term 'microarteriolysis' ${ }^{10}$ be used instead of 'digital sympathectomy'. However, the term 'digital sympathectomy' might be more meaningful to physicians as well as to patients who are not familiar with hand surgery.

Our two cases confirm the studies mentioned above and show that digital sympathectomy (or microarteriolysis) is an effective tool in the treatment of critical ischaemia associated with secondary Raynaud's phenomenon and might prevent the need for amputation.

*Department of Dermatology,

University Hospital of Zurich,

CH-8091 Zurich, Switzerland

†Division of Angiology and Hemostasis and

$\ddagger$ Division of Reconstructive Surgery,

University Hospital of Geneva,

CH-1211 Geneva 14, Switzerland

\section{References}

1 Wigley FM, Wise RA, Seibold JR et al. Intravenous iloprost infusion in patients with Raynaud phenomenon secondary to systemic sclerosis. Ann Intern Med 1994; 120: 199-206.

2 Winston EL, Pariser KM, Miller KB et al. Nifedipine as a therapeutic modality for Raynaud's phenomenon. Arthritis Rheum 1983; 26: 1177-80.

3 Rademaker M, Cooke ED, Almond NE et al. Comparison of intravenous infusions of iloprost and oral nifedipine in treatment of Raynaud's phenomenon in patients with systemic sclerosis: a double blind randomised study. Br Med J 1989; 298: 561-4.

4 Baddeley RM. The place of upper dorsal sympathectomy in the treatment of primary Raynaud's disease. Br J Surg 1965; 52: 426-30.

5 Claes G, Drott C, Göthberg G. Thoracoscopic sympathicotomy for arterial insufficiency. Eur J Surg 1994; 572 (Suppl.): 63-4.

6 Drott C. The history of cervicothoracic sympathectomy. Eur J Surg 1994; 572 (Suppl.): 5-7.

7 Claes G, Drott C, Göthberg G. Endoscopic electrocautery of the thoracic sympathic chain. Scand J Plast Reconstr Surg Hand Surg 1993; 27: 29-33.

8 Flatt AE. Digital artery sympathectomy. J Hand Surg 1980; 5A: $550-6$.

9 Wilgis EFS. Evaluation and treatment of chronic digital ischemia. Ann Surg 1981; 193: 693-6.

10 O'Brien BMcC, Kumar PAV, Mellow CG et al. Radical microarteriolysis in the treatment of vasospastic disorders of the hand, especially scleroderma. J Hand Surg 1992; 17B: 447-52.

11 Kaarela O, Raatikainen T, Carlson S et al. Effect of perivascular sympathectomy on distal adrenergic innervation in the hands of monkeys. J Hand Surg 1991; 16B: 386-8.

\section{Solid persistent facial oedema (Morbihan's disease) following rosacea, successfully treated with isotretinoin and ketotifen}

SIR, The onset of lasting, erythematous, non-pitting oedematous plaques on the upper half of the face is a well-known complication of acne vulgaris and is usually described in the literature as 'solid persistent facial oedema' (SPFO). ${ }^{1}$ A similar clinical condition has been reported in association with rosacea or without any apparent cause with the names of chronic lymphoedema of rosacea, ${ }^{2}$ chronic erythematous facial oedema ${ }^{3}$ or Morbihans's disease. ${ }^{4}$ Recently, Holzle and colleagues suggested that SPFO, chronic lymphoedema of rosacea and Morbihan's disease should be considered as the same entity. ${ }^{5}$

The histological features of SPFO are non-diagnostic, being characterized by oedema of the mid- and papillary dermis, dense perivascular and periadnexal lymphohistiocytic infiltrate with plasma cells and, in some cases, the presence of many mast cells. The physiopathology of this disease is unknown and its treatment often unsatisfactory.

We have recently seen a 45-year-old man who presented with an eruption on his forehead of 12 months' duration. A similar lesion of 1 month's duration had developed on his right cheek. He was otherwise well apart from rosacea, present for 2 years, and the recent onset of a mild diabetes mellitus, controlled by diet. The patient had had mild acne vulgaris when younger. Examination showed a large erythematous oedematous plaque with poorly defined margin on the forehead (Fig. 1 ), and a smaller plaque on the right cheek. Both lesions contained a few pustules. On palpation, the skin was hard and elastic and did not pit. The lesions were asymptomatic but the patient had had transient episodes of swelling. Histopathological examin-ation showed oedema of the papillary and middermis, hypertrophic sebaceous glands and dense perivascular and periadnexal infiltrate composed of lymphocytes and histiocytes with many plasma cells. Toluidine blue staining revealed numerous mast cells. Routine blood chemistry, complement levels, tests for immune complexes, angiotensin-converting enzyme, lysozyme, anti-Leishmania anti-bodies and a skull X-ray were all normal or negative. A diagnosis of SPFO was made and the patient was started on isotretinoin, $0 \cdot 7 \mathrm{mg} /$ $\mathrm{kg}$ per day, with ketotifen, $2 \mathrm{mg} /$ day, as previously recommended. ${ }^{6}$ After 4 months of this therapy, the lesion on the cheek had completely disappeared and the eruption on the forehead was substantially reduced.

Although SPFO following rosacea is rare, it should be included in the differential diagnosis of facial swelling. In our case, clinical, histological and laboratory data excluded diseases such as sarcoidosis, leishmaniasis, erysipelas, Merkelsonn-Rosenthal disease and lymphoma, which may have a similar clinical appearance. The diagnosis of SPFO was also supported by the favourable outcome after combined therapy with isotretinoin and ketotifen. The present report confirms that this combination of drugs is efficacious in SPFO. However, clofazimine and isotretinoin are also said to be effective. ${ }^{7}$ Isotretinoin alone is beneficial in some cases, ${ }^{8,9}$ while drugs such as antibiotics, antihistamines and corticosteroids have been tried in a variety of combinations but do not appear to have any advantage over the use of isotretinoin with either ketotifen or clofazimine.

$\begin{array}{lr}\text { Department of Dermatology } & \text { C.MAZZATENTA } \\ \text { of Siena University, } & \text { G.GIORGINo } \\ \text { Viale Bracci, I-5310o Siena, } & \text { P.RubeGNI } \\ \text { Italy } & \text { G.DE AloE } \\ \text { E-mail: mazzatenta@unisi.it } & \text { M.FimianI }\end{array}$


Figure 1. An oedematous plaque is evident on the forehead.

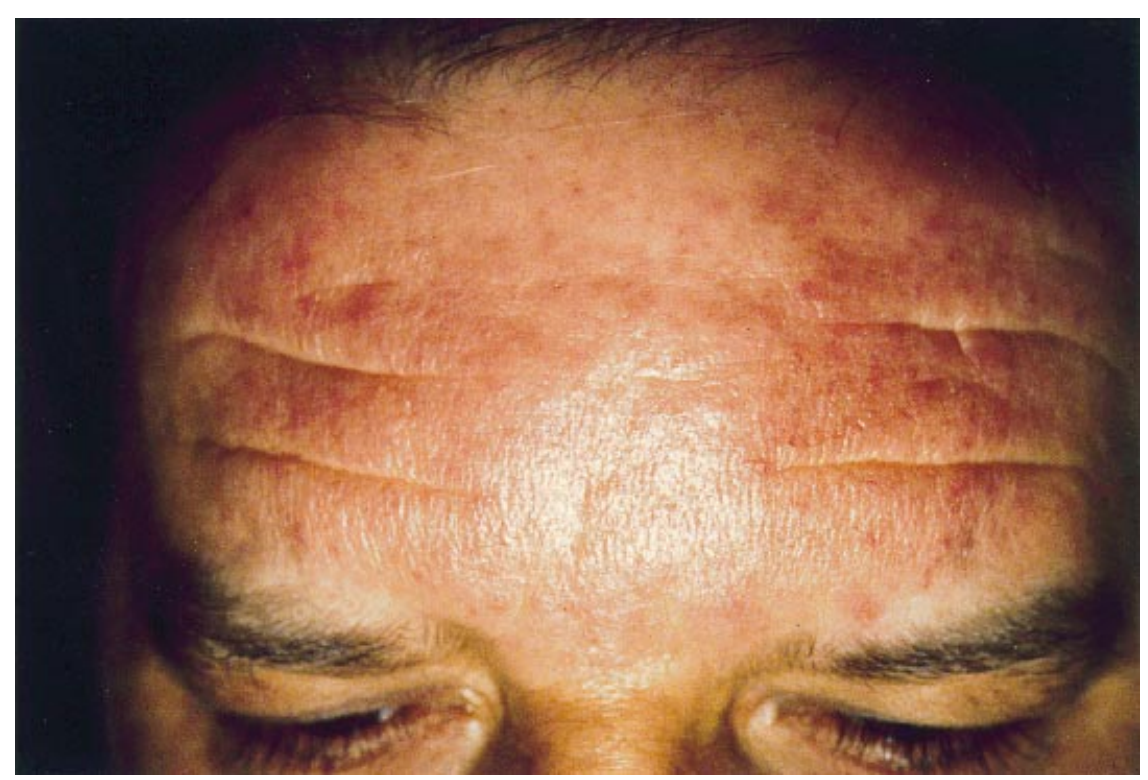

\section{References}

1 Dwyer C, Dick F. Facial oedema and acne vulgaris. Br J Dermatol 1992; 127: 188-9.

2 Marks R. Rosacea, flushing and perioral dermatitis. In: Textbook of Dermatology (Champion RH, Burton LJ, Ebling FJG, eds), 5th edn, Vol. 3. Oxford: Blackwell Scientific Publications, 1992; 1855.

3 Laugier P, Gilardi S. L'oedème érythémateux chronique facial supérieur (Degos). Ann Dermatol Venereol 1981; 108: 507-13.

4 Bundino S, Zina AM, Barberis L, Pippione M. Su un caso di malattia di Morbihan (edema eritematoso cronico faciale superiore). G Ital Dermatol Venereol 1991; 126: 511-14.

5 Holzle E, Jansen T, Plewig G. Morbus Morbihan-chronisch persistierendes Erythem und Odem des Gesichts. Hautarzt 1995; 46: 796-8.

6 Jungfer B, Jansen T, Przybilla B et al . Solid persistent facial edema of acne: successful treatment with isotretinoin and ketotifen. Dermatology 1993; 187: 34-7.

7 Helander I, Heikki JA. Solid facial edema as a complication of acne vulgaris: treatment with isotretinoin and clofazimine. Acta Derm Venereol (Stockh) 1987; 67: 535-7.

8 Humbert P, Delaporte E, Drobacheff C et al. Oedème dur facial associé à l'acné vulgaire. Efficacité thérapeutique de l'isotrétinoine. Ann Dermatol Venereol 1990; 117: 527-32.

9 Friedman SJ, Fox BJ, Albert HL. Solid facial edema as a complication of acne vulgaris: treatment with isotretinoin. J Am Acad Dermatol 1986; 15: 286-9.

\section{High-dose ranitidine is ineffective in the treatment of psoriasis}

SIR, Various treatments have been developed for psoriasis over recent decades, including the use of immunosuppressive agents. ${ }^{1}$ Recently, ranitidine, a histamine $\mathrm{H}_{2}$-receptor antagonist, has been reported to be of benefit in psoriasis. ${ }^{2-4}$ It is thought to work through an immunomodulatory action, although the exact mechanisms have not been delineated. This study was carried out to assess the efficacy of ranitidine in the treatment of psoriasis using a double-blind, placebocontrolled study design.
Fifty patients with stable, plaque-type psoriasis, involving up to $10 \%$ of the body surface, were enrolled in the study. They had received no topical or systemic treatment for the previous 4 weeks. Exclusion criteria included patients who were pregnant or lactating, or who had renal and hepatic disease. The research protocol was approved by the ethics committee of Akdeniz University, and all patients gave signed informed consent. Patients were randomly allocated to treatment groups equally, and received either placebo, or ranitidine, $300 \mathrm{mg}$, twice a day for 4 months. No concurrent topical or systemic treatments were allowed. Patients were evaluated at monthly intervals. At each visit, assessment of the severity of the disease was made by the same clinician, based on the psoriasis area and severity index (PASI). Differences in PASI scores between groups were tested using Student's $t$-test and the Mann-Whitney $U$-test. To test the changes in groups from baseline to post-treatment, the paired $t$-test was used. Data are presented as means \pm SEM. $P<0.05$ was considered to be statistically significant.

Fourteen ranitidine-treated and 14 placebo-treated patients completed the scheduled study period of 4 months, and were evaluated for efficacy of the treatment. Treatment groups were

Table 1. Demographic and clinical characteristics of the treatment groups (mean \pm SEM)

\begin{tabular}{|c|c|c|}
\hline & $\begin{array}{l}\text { Ranitidine } \\
\quad(n=14)\end{array}$ & $\begin{array}{l}\text { Placebo } \\
(n=14)\end{array}$ \\
\hline Age (years) & $45 \cdot 85 \pm 4 \cdot 57$ & $34 \cdot 92 \pm 3 \cdot 37$ \\
\hline \multicolumn{3}{|l|}{ Sex } \\
\hline Male & 9 & 5 \\
\hline Female & 5 & 9 \\
\hline Disease duration (years) & $14 \cdot 25 \pm 3 \cdot 5$ & $10 \cdot 96 \pm 2 \cdot 68$ \\
\hline PASI baseline & $12 \cdot 31 \pm 1 \cdot 71$ & $11 \cdot 55 \pm 1 \cdot 17$ \\
\hline
\end{tabular}




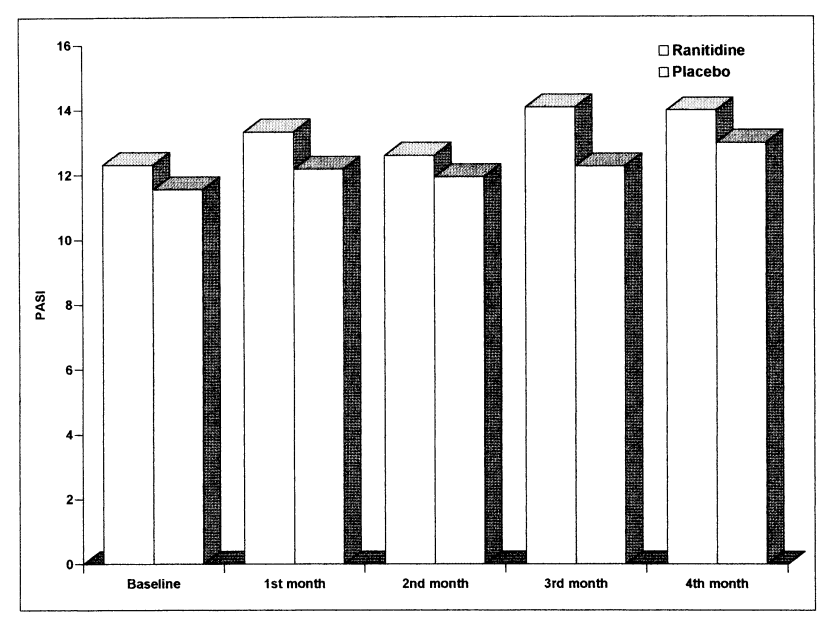

Figure 1. Mean PASI scores in ranitidine and placebo groups undergoing treatment.

similar regarding sex and age, duration and severity of the disease (Table 1). Twenty-two patients were withdrawn before 4 months because of failing to attend for review at the correct times or for using prohibited concomitant medication. No patient was withdrawn due to an adverse event or worsening of the disease. The mean PASI scores in each group undergoing treatment are given in Fig. 1. Baseline and post-treatment mean PASI scores were $12 \cdot 31 \pm 1 \cdot 71$ and $13 \cdot 96 \pm 2 \cdot 13$ in the ranitidine group and $11.55 \pm 1 \cdot 17$ and $12.97 \pm 1.53$ in the placebo group. No significant differences were noted between the mean baseline and post-treatment PASI scores in each treatment group. The mean PASI scores did not show any statistically significant changes from baseline to first month, first month to second month, second month to third month, and third month to post-treatment in each group. In addition, there were no statistically significant differences in the mean baseline, first, second, third and post-treatment PASI scores between the ranitidine and placebo groups.

In this randomized, double-blind study we have shown that ranitidine is not effective in the treatment of psoriasis. Clinical trials using $\mathrm{H}_{2}$-receptor antagonists in psoriasis have given various degrees of success. ${ }^{2-8}$ Previous studies using cimetidine, administered for a short time, were disappointing. ${ }^{7,8}$ In contrast, Nielsen et $a .^{2}$ and Witkamp et al. ${ }^{3}$ have reported beneficial effects for ranitidine given for 4 months. They suggested that long-term high-dose ranitidine improves psoriasis after a lag time of 1-3 months and that the unsuccessful results for cimetidine may be due to the short treatment period. Recently, Kristensen et al. ${ }^{4}$ reported the results of an open, uncontrolled study in which ranitidine was employed in a dosage of $600 \mathrm{mg} /$ day for 6 months. The authors pointed out an initial deterioration of the disease in the first month of treatment. Subsequently, a statistically significant reduction at the mean PASI score was observed at the third month of treatment. In our study, seven patients in each group showed worsening of their disease within the first month of treatment, but an increase in the mean PASI scores in each group was not significant. No significant reductions were noted in mean posttreatment PASI scores in each group. In the present study, ranitidine did not produce an effect superior to that of placebo.

Cell-mediated immunity appears to play an important part in the pathogenesis of psoriasis. ${ }^{1,5}$ Ranitidine might be expected to be effective in the treatment of psoriasis because of its immunomodulatory effects. Despite promising results of open and uncontrolled studies, we found that systemic ranitidine is not an effective alternative in the treatment of plaquetype psoriasis.

\section{Acknowledgments}

The authors would like to thank the Research Foundation of Akdeniz University for financial support of this study, and Fako Ilaçlar A.Ş.-Abfar who supplied both placebo and ranitidine tablets.

Akdeniz University,

L.ÇETIN

Medical Faculty,

E. YILMAZ

Department of Dermatology,

E.ALPSOY

07070 Antalya, Turkey

E.BAŞARAN

\section{References}

1 Gottlieb AB. Immunologic mechanisms in psoriasis. J Invest Dermatol 1990; 95: 18-19S.

2 Nielsen HJ, Nielsen H, Georgsen J. Ranitidine for improvement of treatment-resistant psoriasis. Arch Dermatol 1991; 127: 270.

3 Witkamp L, Velthuis PJ, Verhaegen MEJM et al. An open prospective clinical trial with systemic ranitidine in the treatment of psoriasis. $J$ Am Acad Dermatol 1993; 28: 778-81.

4 Kristensen JK, Petersen LJ, Hansen U et al. Systemic high-dose ranitidine in the treatment of psoriasis: an open prospective clinical trial. Br J Dermatol 1995; 133: 905-8.

5 Nielsen HJ. Histamine and histamine type-2 receptor antagonists in psoriasis. Dan Bed Bull 1991; 38: 478-80.

6 Giacosa A, Farris A, Cheli R. Cimetidine and psoriasis. Lancet 1978; ii: $1211-12$.

7 Long PR, Miller OF. Cimetidine and psoriasis. Arch Dermatol 1981; 117: 523.

8 Merk H, Goerz G, Runne U et al. Cimetidine and chlorpheniramine in the treatment of psoriasis. Dermatologica 1983; 166: 94-6.

\section{Focal neurological signs and symptoms induced by} interferon-alpha in two patients with malignant melanoma

SIR, Interferon-alpha therapy is an approved treatment for metastatic malignant melanoma and an adjuvant treatment for high-risk malignant melanoma. ${ }^{1}$ The most common sideeffects are fatigue and influenza-like symptoms, ${ }^{2}$ but a few patients have been reported with ischaemic reactions. We read with interest the article by Bachmeyer et al. ${ }^{3}$ and report two patients who had focal neurological signs and symptoms possibly induced by interferon-alpha.

A 41-year-old man with no risk factors for vascular disease was treated for malignant melanoma with lymphoblastoid 
interferon-alpha, 9 million international units (IU) subcutaneously (s.c.) on alternate days. Two months after the start of this treatment and about $2 \mathrm{~h}$ after an interferon injection, the patient suffered a cerebral stroke with paresis of the right arm and leg. Cranial computed tomography (CT) and nuclear magnetic resonance scans demonstrated an ischaemic area in the region of the pons. The symptoms improved gradually over a period of 6 months and no further event occurred. Interferon therapy was continued for another 10 months at a reduced dose of 3 million IU on alternate days. The patient died 31 months after the onset of interferon therapy due to widespread metastatic disease. No atherosclerotic plaques in cranial arteries or brain-stem metastases were demonstrated on post-mortem.

A 57-year-old woman with malignant melanoma, who had no risk factors for vascular disease, received combined chemoimmunotherapy with dacarbazine and recombinant interferon-alpha $2 \mathrm{~b}$ ( 3 million IU s.c.three times a week). Five days after the start of treatment and $3 \mathrm{~h}$ after the interferon injection, she noticed weakness and sensory loss in the left forearm and hand. This completely resolved within $1 \mathrm{~h}$. Two similar episodes occurred, which were more severe and extended to the left shoulder, 4 and 7 weeks later. Unfortunately, the patient did not consult a physician at the time. Detailed neurological examination several days after the last episode showed no abnormality and cranial CT scans were normal. The dose of interferon-alpha was reduced to 1 million IU three times a week and there have been no further neurological complaints after 10 months of follow-up.

We report two patients who experienced focal neurological signs and symptoms $2-3 \mathrm{~h}$ after s.c. interferon-alpha. Although there is no proof that this treatment directly caused the symptoms, the time sequence suggests an association. Our observation is in agreement with reports in which interferon-alpha has induced ischaemic reactions in various tissues. These include cutaneous necrosis at an injection site, $^{2,4,5}$ Raynaud's phenomenon and digital necrosis, ${ }^{3,6,7}$ ischaemia of the colon, ${ }^{8}$ and ischaemic optic neuropathy. ${ }^{9}$

To explain the pathogenesis of such reactions, Reid et al. ${ }^{6}$ postulate that interferon-alpha may cause a vasculitis resulting in acral necrosis. However, in both of our patients, as well as in other cases, inflammatory or allergic mechanisms due to the interferon are unlikely, as the treatment could be subsequently continued without further side-effects. ${ }^{4,5}$ Interferon-alpha may increase blood coagulability as, in two patients with digital necrosis, thrombotic occlusion of small dermal vessels without signs for inflammation has been reported. ${ }^{3}$ The induction of vasospasm by interferon-alpha is an alternative pathogenetic pathway supported by its induction of Raynaud's phenomenon in some patients, ${ }^{3}$ and the dose-dependency of symptoms in our patients, lower doses being well tolerated.

As adjuvant high-dose therapy with interferon-alpha has been approved for patients with high-risk malignant melanoma in the U.S.A., ${ }^{1}$ and will very probably be approved in Europe soon, physicians and patients should be aware of the potential for severe ischaemic side-effects.
Department of Dermatology,

R.A.HERBST

Hannover Medical School,

R.GUTZMER

Ricklinger Strasse 5, D-30449 Hannover,

Germany

*Department of Dermatology,

E.G.JunG*

A.KAPP

J.WEISS

Mannheim Medical School,

Theodor-Kutzer-Ufer,

D-68135 Mannheim,

Germany

\section{References}

1 Kirkwood JM, Strawderman MH, Ernstoff MS et al. Interferon alfa$2 \mathrm{~b}$ adjuvant therapy of high-risk resected cutaneous melanoma: the eastern cooperative oncology group trial EST 1684. J Clin Oncol 1996; 14: 7-17.

2 Asnis LA, Gaspari AA. Cutaneous reactions to recombinant cytokine therapy. J Am Acad Dermatol 1995; 33: 393-410.

3 Bachmeyer C, Farge D, Gluckman E et al. Raynaud's phenomenon and digital necrosis induced by interferon-alpha. Br J Dermatol 1996; 135: 481-3.

4 Rasokat H, Bendick C, Wemmer U, Steigleder GK. Aseptische Hautnekrose nach subcutaner Injektion von Interferon-alpha. Dtsch Med Wochenschr 1989; 114: 458-60.

5 Konohana A, Hasegawa Y, Kobayashi T. Cutaneous ulcerations resulting from intramuscular injections of interferon-alfa. J Am Acad Dermatol 1996; 35: 788-9.

6 Reid TJ, Lombardo FA, Redmond J et al. Digital vasculitis associated with interferon therapy. Am J Med 1992; 92: 702-3.

7 Roy V, Newland AC. Raynaud's phenomenon and cryoglobulinaemia associated with the use of recombinant human alphainterferon. Lancet 1988; i: 944-5.

8 Sparano JA, Dutcher JP, Kaleya R et al. Colonic ischemia complicating immunotherapy with interleukin-2 and interferon-alpha. Cancer 1991; 68: 1538-44.

9 Purvin VA. Anterior ischemic optic neuropathy secondary to interferon alpha. Arch Ophthalmol 1995; 113: 1041-4.

\section{Subungual blue naevus}

SIR, Blue naevi occur most commonly in the skin, but they have also been found in oral mucosa, the vagina, penis, sclera, uterine cervix and prostate. ${ }^{1-4}$ Blue naevus has not been previously reported to involve the nail apparatus.

We report a 20-year-old man who presented with a subungual pigmented lesion of the right great toe. The lesion had been present since birth, was asymptomatic, and had grown slowly. During the few months prior to presentation, the nodule had increased in size and had become slightly painful. There was no history of trauma. Examination showed a pigmented round subungual nodule, $0.9 \mathrm{~cm}$ in diameter, that elevated the distal border of the nail plate (Fig. 1). The nodule showed regular bluish-black discoloration, emerged from under the nail edge, and involved the hyponychium. There was no lymphadenopathy. The lesion was excised and histopathology demonstrated elongated, slightly spindly cells with long branching dendritic processes. These cells were arranged in fascicles and were dispersed as solitary units among collagen bundles. The full thickness of the mesenchymal nail bed and the dermis were involved. No junctional component was seen. Dermal 


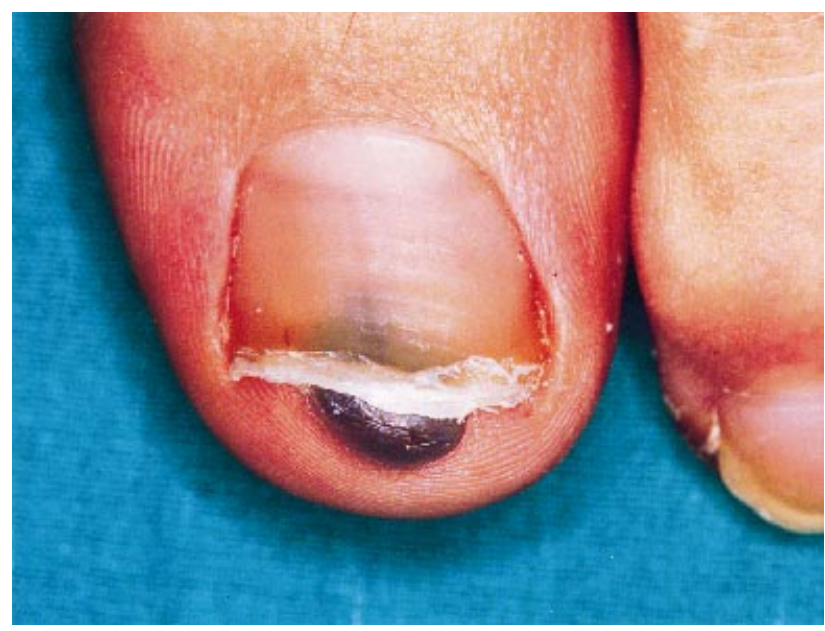

Figure 1. A bluish-black nodule is evident at the distal edge of the nail bed, and elevates the nail plate.

melanocytes were mostly orientated with their long axes parallel to the epidermis and many were filled with fine granules of melanin (Fig. 2). Numerous melanin-laden macrophages were interspersed among the melanocytes. The stroma of the lesion consisted of sclerotic collagen bundles surrounding aggregates of melanocytes. No melanocyte atypia or mitotic figures were seen.

Subungual blue naevus is not described in standard textbooks. ${ }^{5,6}$ Baran and Dawber illustrate a blue naevus involving the proximal nail fold of a great toe in a child as an example of pseudomalignancy in the differential diagnosis of subungual melanoma, ${ }^{7}$ a case supplied by Dr Kerl of the University of Graz, Austria. The patient was a 4-year-old girl with KlippelTrenaunay syndrome, who showed a sharply demarcated irregular black area, $1 \cdot 2 \times 0 \cdot 4 \mathrm{~cm}$, involving the distal phalanx of the left first toe, with several pinhead-sized satellite nodules in the adjacent skin. The lymph nodes in the left groin were palpable. Amputation of the left big toe and dissection of the lymph nodes of the left groin were performed. The periungual lesion was shown on histology to be a combined naevus, comprising a Clark's naevus at the dermoepidermal junction and a blue naevus in the dermis. Epithelioid dendritic and spindle-shaped melanocytes were found in the capsule and in some parts of certain lymph nodes. The case was interpreted as an example of a periungual combined naevus with 'benign' lymph-node metastases from the blue naevus component. We have studied these histopathology sections (provided by Dr Soyer of the University of Graz), and concur with the diagnosis. This patient is now 16 years old and remains well with no evidence of recurrence of metastatic disease. Salasche and Garland described a melanotic lesion involving the thumb nail, said to be a subungual blue naevus, but there was no histology. ${ }^{8}$

The differential diagnosis of subungual melanocytic lesions should always include subungual malignant melanoma. In our case, melanoma in situ could be ruled out because no junctional melanocytic component was present and the findings in the dermis were typical for a blue naevus.

Departments of Dermatology,

S.VIDAL H.M.C. Gómez-Ulla,

*Hospital Universitario San Carlos, and

†Fundación Jiménez Diaz,

Madrid, Spain and

$\ddagger$ Nail Disease Centre, Cannes, France

A.SANZ

B.HERNÁNDEZ

E.SÁNCHEZ Yus*

L.REQUENA $\dagger$

R.BARAN†

\section{References}

1 Kjaerheim A, Martinez MG, Montes LF. Blue nevus of the oral cavity. An electronmicroscopic study. Oral Surg 1970; 29: 718-28.

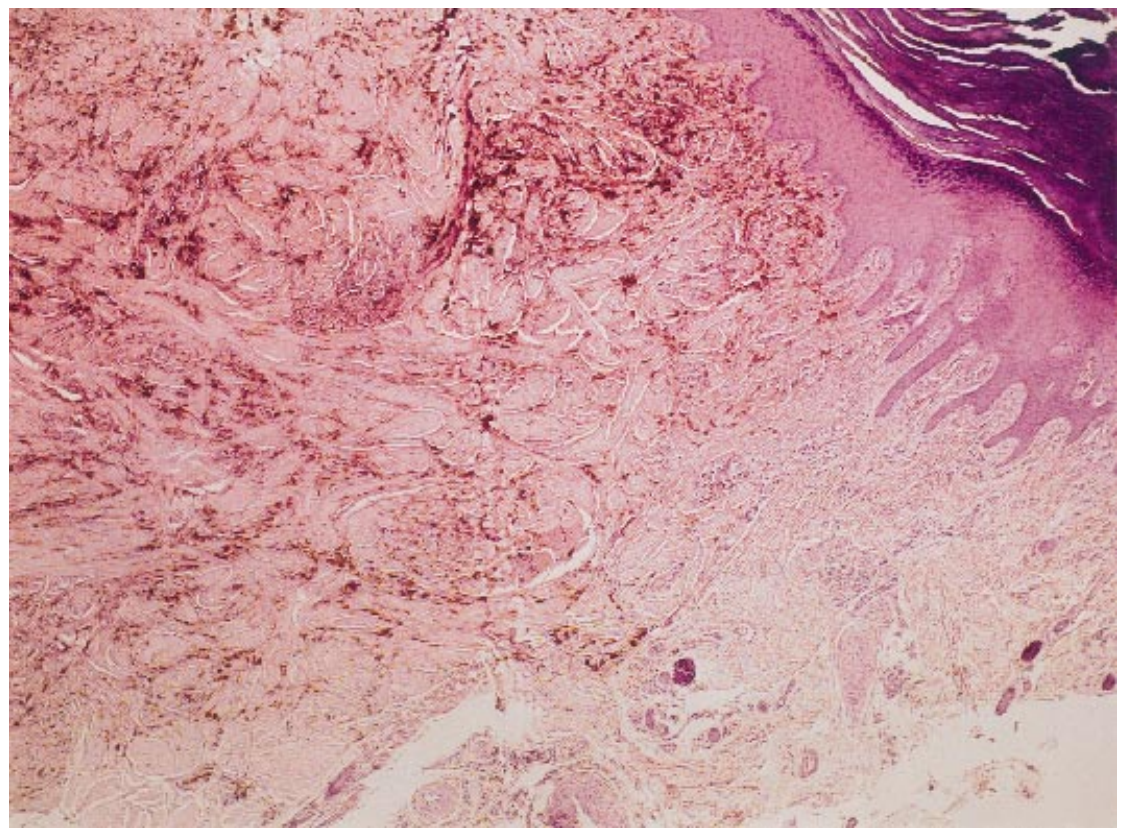

Figure 2. Proliferation of hyperpigmented bipolar dendritic spindle cells is seen to involve the full thickness of the dermis (haematoxylin and eosin $\times 40$ ). 
2 Smith PR, Brockhurst RJ. Cellular blue nevus of the sclera. Arch Ophthalmol 1976; 94: 618-20.

3 Patel DS, Bhagavan BS. Blue nevus of the uterine cervix. Hum Pathol 1985; 16: 79-86.

4 Hasson A, Gutierrez MC, Marin L et al. Blue nevi on the prepuce and glands penis. Skin Cancer 1990; 5: 15-19.

5 Zaias N. The Nail in Health and Disease, 2nd edn. Norwalk, CT: Appleton \& Lange, 1990.

6 Baran R, Dawber RPR. Diseases of the Nails and their Management, 2nd edn. Oxford: Blackwell Scientific Publications, 1994.

7 Soyer HP, Kerl H. Congenitaler blauer Nävus mit Lymphknotenmetastases und Klippel-trenaunay-Syndrom. In: First Congress of European Society of Pediatric Dermatology, Münster, 4-7 October 1984. Clinical Case Reports (Happle R, Traupe H, eds), 28-9.

8 Salasche S, Garland LD. Tumors of the nail. Dermatol Clin 1985; 3: 501-19.

\section{Idiopathic calcinosis cutis of the penis}

SIR, Calcinosis of the scrotum is well documented, ${ }^{1}$ but calcinosis of the penis is rare. It usually affects the penile subcutis or corpora rather than the overlying skin. Of the few cases of penile calcification that have been reported, most have been secondary to a recognized underlying pathological process such as Peyronie's disease, or have followed trauma and thus were dystrophic in nature. We present a patient with idiopathic dermal calcinosis of the penis. Similar clinical and pathological features have been described in only one previous case. $^{2}$

A 16-year-old boy was referred with an 8-month history of asymptomatic penile papules. He had no systemic symptoms and there was no history of trauma to the penis or of an inflammatory process in the penile skin. Examination revealed a 4-mm diameter smooth hard papule on the shaft of the penis, surrounded by a cluster of smaller papules (Fig. 1). General examination was normal. A diagnosis of inclusion cysts was made. The largest papule was biopsied, and histology showed a mass of calcified debris with focal ossification in the dermis, surrounded by a foreign body reaction with numerous giant cells and a rim of hyaline fibrous tissue (Fig. 2 ). There was no evidence of an epithelial cyst lining or an adnexal tumour. Routine haematological and biochemical tests were normal.

Calcification of the skin and other tissues can be classified into: dystrophic, metastatic and idiopathic. Dystrophic calcification is associated with an underlying tissue abnormality, metastatic with elevated levels of calcium or phosphate in the blood, but with idiopathic calcification, no underlying cause can be found.

Calcinosis of the penis is usually the result of dystrophic calcification and has been described in association with trauma, ${ }^{3}$ self-injection with papaverine for erectile impotence, ${ }^{4}$ and Peyronie's disease, in which one or more irregular dense fibrous plaques occur on the penile shaft with varying degrees of calcification or ossification. Katoh et al. described a patient with a calcified penile nodule thought to result from calcification of a syringoma. $^{5}$ Histological examination showed several foci of calcification, some, but not all, of

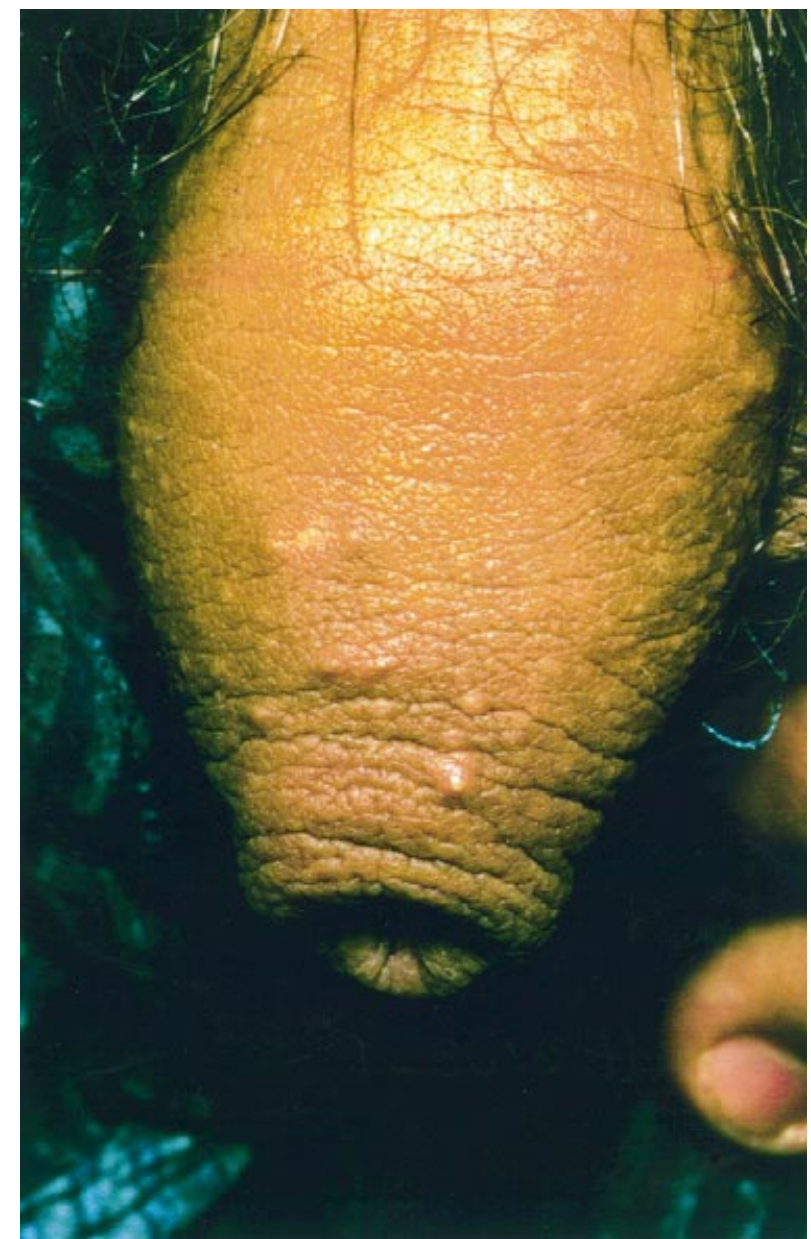

Figure 1. A cluster of smooth hard papules is seen on the penile shaft.

which were surrounded by epithelial cyst walls. Metastatic calcification of the penis has been described in six of 32 patients with end-stage renal failure and secondary hyperparathyroidism who presented with erectile impotence. ${ }^{6}$ Our patient appears to have idiopathic calcification as no preexisting lesion could be identified. In one previous similar case of idiopathic penile calcification, there was dermal calcification with no evidence of associated cysts nor remnants of adnexal structures. ${ }^{2}$

The pathogenesis of idiopathic penile calcification may be similar to that proposed for idiopathic scrotal calcinosis, a more common disease that affects men of a similar age group to our patient. Several authors have suggested that scrotal calcinosis is the result of changes in pre-existing epidermal cysts or eccrine duct milia. ${ }^{7,8}$ The keratinous contents of such cysts become inspissated and undergo dystrophic calcification which results in attenuation and resorption of the cyst walls leaving the calcified material behind as a 'tombstone'.

Department of Dermatology,

Western Infirmary,

Glasgow G11 6NT, U.K.
T.LuCKE

M.FALLOWFIELD P.McHENRY 


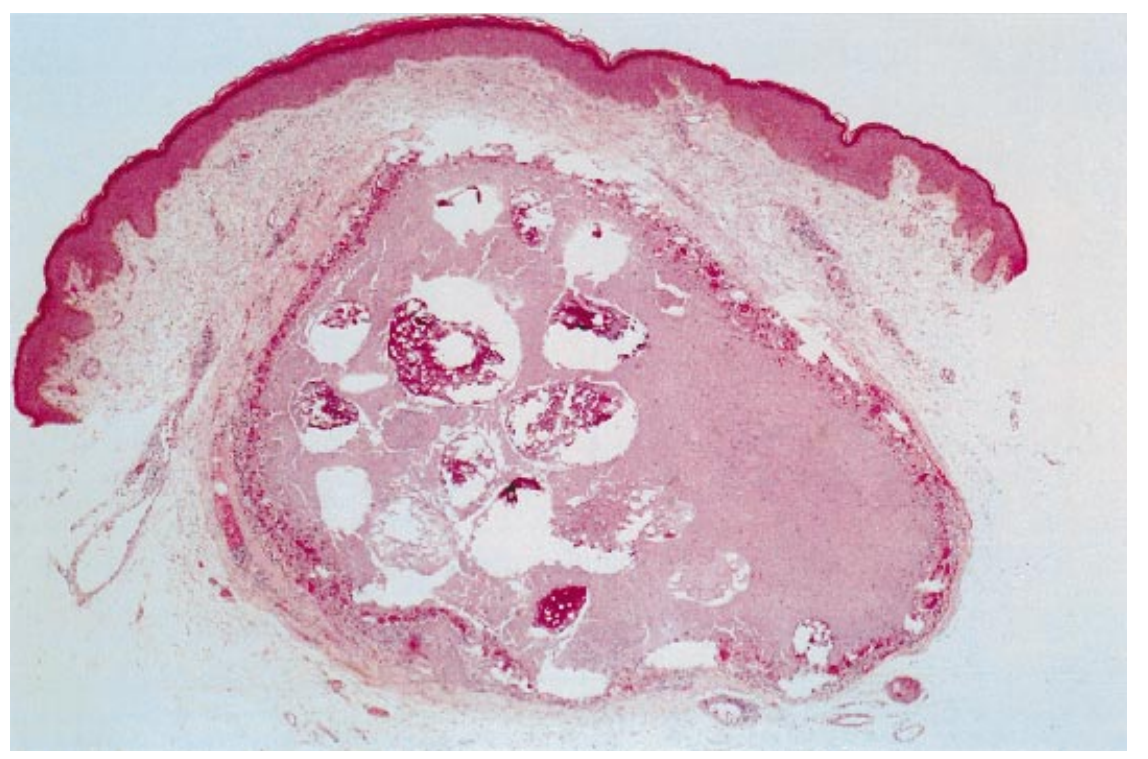

Figure 2. Photomicrograph showing amorphous calcified debris surrounded by foreign body giant cells (haematoxylin and eosin: $\times 25)$.

\section{References}

1 Fisher BK, Dvoretzky I. Idiopathic calcinosis of the scrotum. Arch Dermatol 1978; 114: 957.

2 Hutchinson IF, Abel BJ, Susskind W. Idiopathic calcinosis cutis of the penis. Br J Dermatol 1980; 102: 341-3.

3 Joffe N. Calcification of the penis. Br J Radiol 1961; 34: 198-9.

4 Pery M, Rosenberger A, Kaftori JK, Vardi Y. Intracorporeal calcifications after self-injection with papaverine. Radiology 1990; 176: 813.

5 Katoh N, Okabayashi K, Wakabayashi S, et al. Dystrophic calcinosis of the penis. J Dermatol 1993; 20: 114-17.

6 Dalal S, Gandhi VC, Yu AW, et al. Penile calcification in maintenance hemodialysis patients. Urology 1992; 40: 422-4.

7 Song DH, Lee KH, Kang WH. Idiopathic calcinosis of the scrotum: histopathologic observations of fifty one nodules. I Am Acad Dermatol 1988; 19: 1095-101.

8 Dare AJ, Axelsen RA. Scrotal calcinosis: origin from dystrophic calcification of eccrine duct milia. J Cutan Pathol 1988; 15: 142-9.

\section{Eyelid metastasis as the presenting sign of recurrent carcinoma of the breast}

SIR, Carcinoma of the breast frequently involves the skin, with cutaneous lesions being seen in about $25 \%$ of patients with metastatic disease. Up to eight distinct clinicopathological types of cutaneous involvement have been described for breast carcinoma, including metastatic eyelid disease. ${ }^{1}$ Metastatic breast carcinoma in the eyelid seems to be very rare, and only a few cases have been reported..$^{2,3}$ We present a woman with carcinoma of the breast in whom eyelid metastasis was the presenting sign of recurrent disease.

A 52-year-old woman was admitted in June 1990 with a palpable mass measuring $2 \mathrm{~cm}$ in diameter in her right breast. A biopsy revealed an invasive ductal breast carcinoma. Breastpreserving surgery with segmental resection and dissection of the right axilla was performed. None of the 12 axillary lymph nodes examined had metastatic involvement. Local radiotherapy and adjuvant chemotherapy were administered.
The patient remained free of disease for 5 years. In December 1995, she was referred to the dermatology clinic because of progressive swelling of the right upper and lower eyelids of 3 months' duration. Two months later, several cutaneous nodules appeared on the neck and trunk. On examination, the right upper and lower eyelids were diffusely swollen with reddening of the skin and showed a palpable, homogeneous, firm consistency (Fig. 1).

Biopsy specimens of both the lower right eyelid and a cutaneous nodule on the trunk revealed metastatic carcinoma. The immunohistochemical study was compatible with a primary breast location. Abdominal computed tomographic scan revealed disseminated liver metastases. A bone scan showed intense accumulations in the left clavicle, fourth dorsal vertebra and several ribs. Serum mucinous-like carcinoma antigen levels were markedly elevated. According to the patient's wishes, only symptomatic, palliative treatment was given. She died 4 months after the diagnosis of eyelid metastasis.

Metastasis to the eyelids is rare, accounting for less than $1 \%$ of malignant eyelid lesions. ${ }^{4,5}$ Breast carcinoma accounts for $35-65 \%$ of cases in different series. In a recent review of the literature, Zhang et al. ${ }^{6}$ found only 36 cases of eyelid metastasis from breast cancer. The site of the eyelid metastasis was the right side in 22 cases $(61 \%)$, as observed in our patient. The reason for preferential involvement of the right eyelid, if any, is unknown. Eyelid metastasis often occurs in the advanced stages of malignant tumours, and they are usually a sign of poor prognosis. Among the 36 previously reported cases from breast cancer, only nine (25\%) showed metastasis of the eyelid alone at presentation.

Riley has classified eyelid metastasis into three types according to clinical features. ${ }^{7}$ Type 1 show solitary subcutaneous nodules, non-tender and non-inflamed. Fifteen of 37 (41\%) reported cases of breast eyelid metastasis had this type of clinical presentation. Solitary nodules may be mistaken clinically for chalazion. Type 2 is a non-tender thickening and 


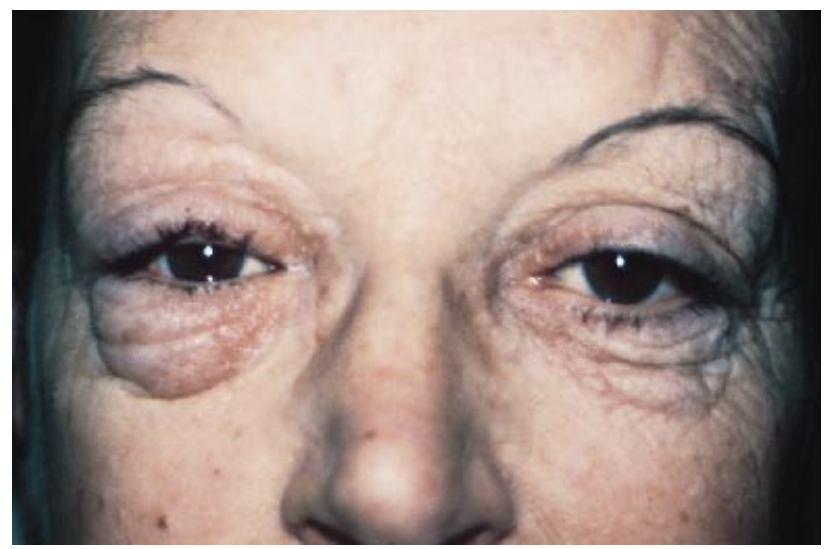

Figure 1. Diffuse swelling is evident of the upper and lower eyelids on the right side.

induration in the eyelid, which is typically observed in breast carcinoma. This type has been observed in 22 cases (59\%) of eyelid metastasis from mammary cancer, including the present case. Type 3 lesions are ulcerative. This type has not been reported so far for breast carcinoma metastasis to the eyelid.

\author{
Departments of Dermatology and \\ *Pathology, \\ La Paz University Hospital, \\ Pasio Castellana 261, \\ 28046 Madrid, \\ Spain
}

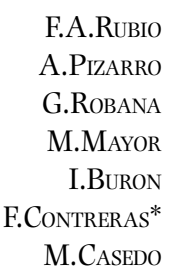

\section{References}

1 Schwartz RA. Cutaneous metastatic disease. J Am Acad Dermatol 1995; 33: 161-82.

2 Weimar VM, Ceilley IR, Hurwitz CN. Breast carcinoma metastatic to the eyelids. Arch Dermatol 1978; 114: 461.

3 Rosenblum GA. Metastatic breast cancer in the eyelid. Cutis 1983; 31: 411-15.

4 Mansour AM. Metastatic lid disease. Orbit 1985; 4: 247-52.

5 Arnold AC, Bullock JD, Foss RY. Metastatic eyelid carcinoma. Ophthalmology 1985; 92: 114-19.

6 Zhang GJ, Adachi I, Yin DF et al. Eyelid metastasis from breast cancer showing marked response to chemotherapy. Jpn J Clin Oncol 1995; 25: 10-15.

7 Riley FC. Metastatic tumors of the eyelid. Am J Ophthalmol 1970; 69: 259-64.

\section{Necrolytic migratory erythema-like eruption in zinc deficiency associated with alcoholic liver disease}

SIR, We read with interest the paper by Sinclair and Reynolds on necrolytic migratory erythema (NME) and zinc deficiency. ${ }^{1}$ We would like to point out that, in patients with alcoholic liver disease, a pseudoglucagonoma syndrome ${ }^{2}$ is highly suggestive of zinc deficiency. In northern France, alcoholic cirrhosis is frequent, and we are interested in its cutaneous manifestations. ${ }^{3}$ Over the last few years, we have had the opportunity to see several patients with advanced cirrhosis. Certain patients develop an extensive, scaling, erosive dermatitis (Figs 1 and 2a) involving predominantly the peri-orificial areas (Fig. 2b) but also the limbs and the trunk, and associated with bilateral angular cheilitis and glossitis. Skin biopsies specimens showed similar histopathological findings of parakeratosis, acanthosis, necrosis of upper epidermal keratinocytes and a lymphocytic infiltrate in the papillary dermis. Plasma glucagon levels were always normal and no glucagonomas were detected. Plasma zinc levels were decreased or just below the normal range, and a dramatic improvement was observed in all patients with zinc therapy. Sub-normal levels of plasma zinc do not discount the presence of zinc deficiency. Indeed, only leucocyte zinc concentrations seem to correlate closely with zinc tissue status. ${ }^{4}$

Zinc deficiency may present not only with asteatotic eczema or acrodermatitis enteropathica, but also with a NME-like eruption. It seems likely that some reported cases of NME without glucagonoma in patients with small bowel disorder, ${ }^{5}$ or liver disease, ${ }^{6}$ may have been examples of zinc deficiency. ${ }^{7}$ In these patients, zinc supplements are best given intravenously. In the absence of improvement after 1 week of treatment, essential fatty acids deficiency must be considered. ${ }^{8}$

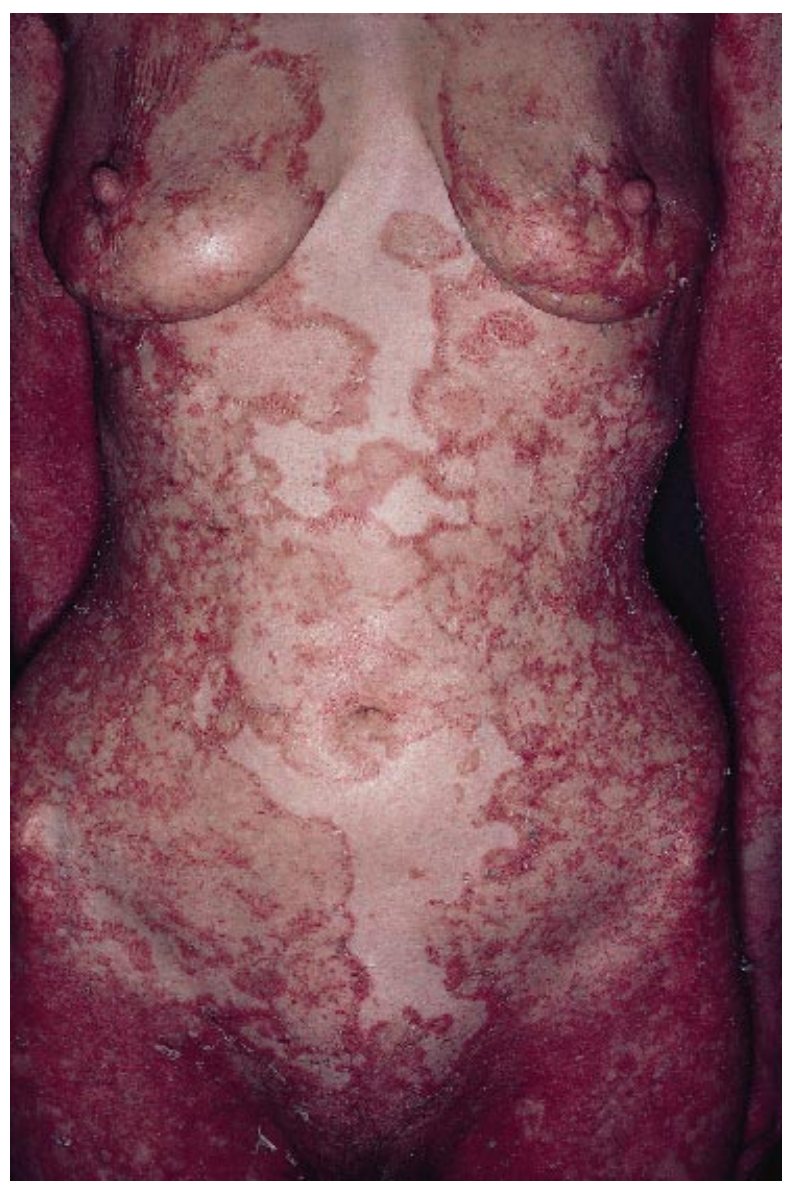

Figure 1. A widespread cutaneous eruption is evident with circinate and serpiginous borders 

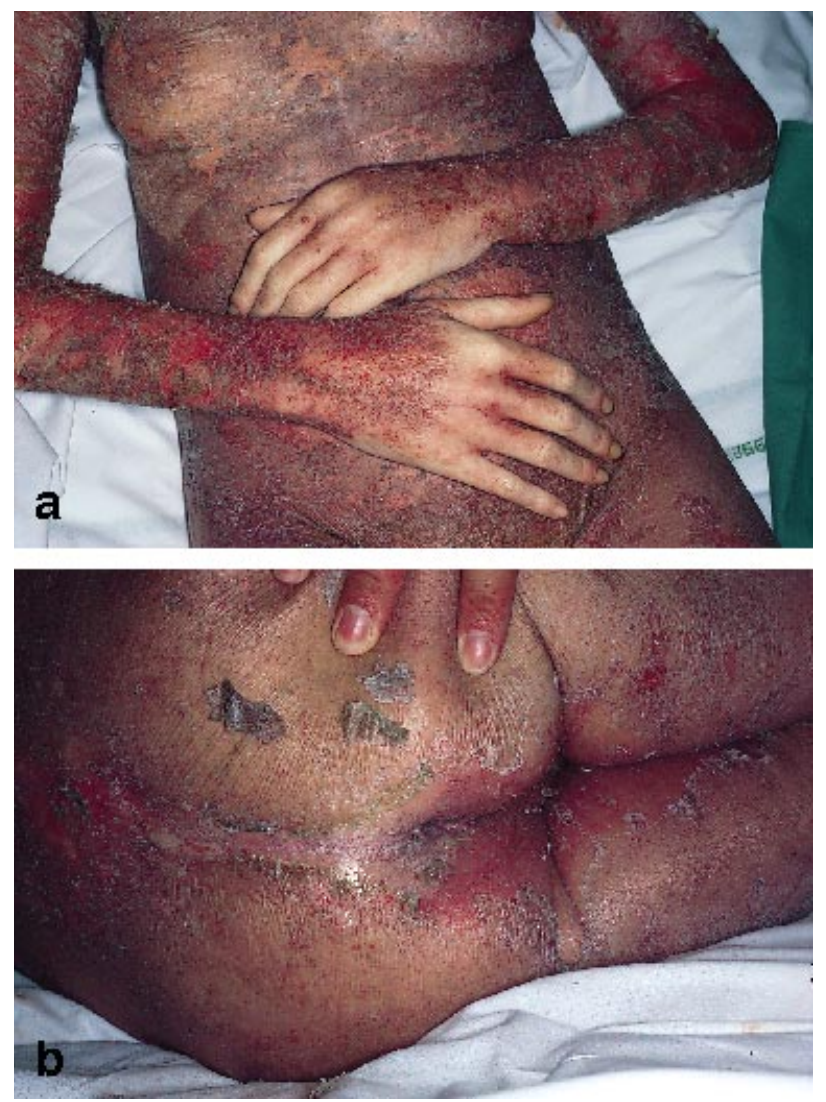

Figure 2. (a) Extensive, erosive, scaling dermatitis is seen. (b) Involvement of the intergluteal cleft is demonstrated

Department of Dermatology,

Claude-Huriez Hospital,

University Hospital Centre,

Lille, France

\section{References}

1 Sinclair SA, Reynolds NJ. Necrolytic migratory erythema and zinc deficiency. Br J Dermatol 1997; 136: 783-5.

2 Schwartz RA. Glucaganoma and pseudoglucaganoma syndromes. Int J Dermatol 1997; 36: 81-9.

3 Gaveau D, Piette F, Cortot A et al. Manifestations cutanées du déficit en zinc dans la cirrhose éthylique. Ann Dermatol Venereol 1997; 114: 39-53.

4 Meadows NJ, Ruse W, Keeling PWN et al. Peripheral blood leucocyte zinc depletion in babies with intrauterine growth retardation. Arch Dis Child 1983; 58: 807-9.

5 Goodenberger DM, Lawley TJ, Strober W et al. Necrolytic migratory erythema without glucagonoma. Arch Dermatol 1979; 115: 1429-32.

6 Hay E, Scanlain NNI, Barnes L. Necrolytic migratory erythema due to zinc deficiency. Br J Dermatol 1992; 127 (Suppl. 40): $57-8$.

7 Marinkovich PM, Botella, Datloff J, Sangueza OP. Necrolytic migratory erythema without glucagonoma in patients with liver disease. J Am Acad Dermatol 1997; 32: 604-8.

8 Blackford S, Wright S, Roberts DL. Necrolytic migratory erythema without glucagonoma: the role of dietary essential fatty acids. $\mathrm{Br} \mathrm{J}$ Dermatol 1991; 125: 460-2.

\section{Trimethoprim-induced linear fixed drug eruption}

SIR, We present a patient with a linear fixed drug eruption (FDE) caused by trimethoprim. A 25-year-old Caucasian woman was referred with a pruritic linear eruption on her right arm. Examination revealed numerous discrete, roundoval-shaped, violaceous macules and oedematous plaques of $1-5 \mathrm{~cm}$ diameter distributed in a linear pattern on the right arm (Fig. 1), extending from the lateral aspect of the dorsum of the fourth and fifth fingers, along the wrist and the extensor surface of the forearm, across the elbow, and up to the right shoulder. Some of the lesions were surmounted by flaccid bullae. This was her third attack in 6 months. Lesions lasted for 10-15 days and healed with residual pigmentation. She had a history of co-trimoxazole intake on the day before the eruption had begun and also of occasional intake during the last 2-3 years because of relapsing tonsillitis. No systemic abnormalities were found on physical and routine laboratory examination. Histopathological examination revealed epidermal spongiosis, exocytosis and dyskeratosis, hydropic degeneration in the epidermal basal layer, pigmentary incontinence, and a mononuclear perivascular inflammatory infiltration with single eosinophils and neutrophils in the upper and mid-dermis, all of which supported the diagnosis of FDE.

After withdrawal of cotrimoxazole and treatment with methylprednisolone $32 \mathrm{mg} /$ day orally for 3 days, lesions cleared leaving residual hyperpigmentation. Four weeks later, an oral challenge with one-eighth of a single co-trimoxazole dose was performed. The previously involved FDE sites reactivated completely with marked violaceous erythema and oedema starting within 1-2 h, and progressed into flaccid bullae (Fig. 2). Four weeks later, topical provocation tests were performed. Tape-stripping occlusive patch testing with co-trimoxazole, trimethoprim and sulphamethoxazole at concentrations of $10 \%, 20 \%$ and $50 \%$ in white petrolatum, with pure petrolatum as the negative control, gave no reaction on previously involved and uninvolved skin. In a repeated open application patch test with the drugs at the same concentrations in dimethyl sulphoxide (DMSO), a positive reaction was seen on previously involved skin sites with trimethoprim 50\%

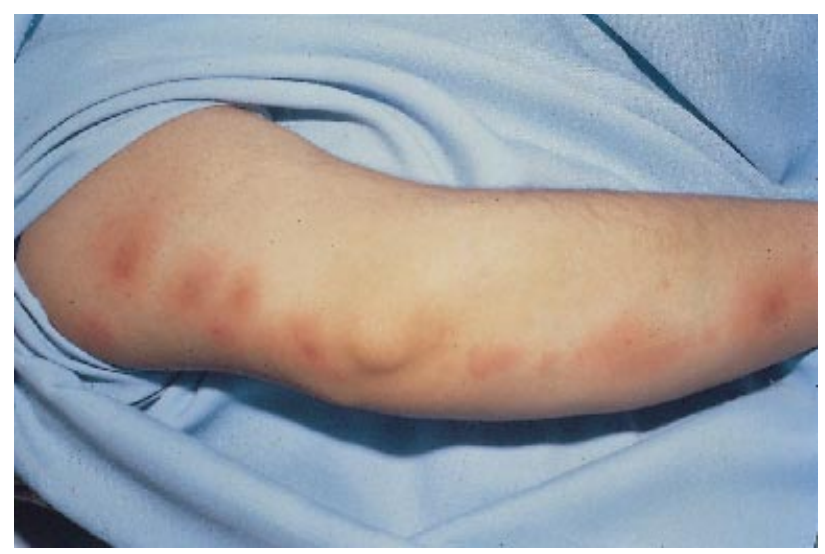

Figure 1. A linear eruption was seen on the right arm at the first visit. 


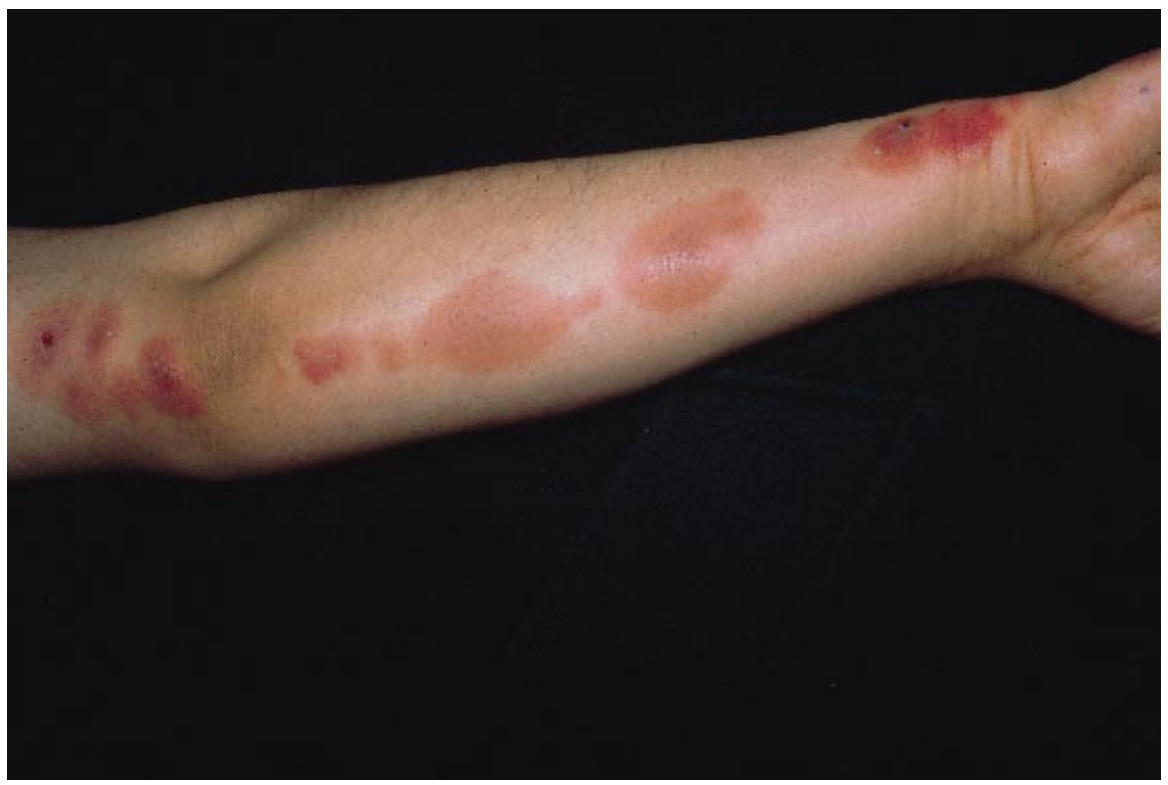

Figure 2. A flare-up reaction occurred on the right arm $24 \mathrm{~h}$ after the oral challenge with one-eighth of a single dose of cotrimoxazole.

and co-trimoxazole $20 \%$ and $50 \%$, starting $\approx 4-5 \mathrm{~h}$ after the second application of the test preparations.

Several less common clinical types of FDE have been reported, with urticarial, nodular, eczematous and erythema multiforme-like lesions, ${ }^{1,2}$ and unusual appearance such as symmetrical pigmenting, non-pigmenting, wandering and pulsating lesions, thoracic lesions following the line of intercostal nerves, and central trunk lesions straddling the mid-line symmetrically. ${ }^{3,4}$ Recently, a single case with a peculiar linear distribution pattern of FDE lesions on the leg due to intramuscular injection of cephazolin was reported. ${ }^{4}$

Several explanations can be found for the linear distribution of the FDE lesions. In the literature, various skin changes have been reported following a linear pattern. ${ }^{5}$ This linearity may be related to the distribution of the dermatomes, Blaschko's lines, tension lines and anatomical structures, and to the Köbner phenomenon occurring after prior injuries or inflammatory reactions such as insect bites, healed herpes zoster or previous cellulitis. $^{5}$ On the extremities, Blaschko's lines and the dermatomes run in a linear pattern and it is difficult to decide whether the skin lesions are consistent with one or the other. The linearity of the previous case of linear FDE on the left leg after intramuscular injection of cephazolin was attributed to the dermatomal distribution of $S_{1}$ nerve roots rather than to Blaschko's lines. ${ }^{4}$ The linearity in our patient may be related either to the distribution along the $C_{8}$ dermatomal region or Blaschko's lines.

Systemic provocation is still the most reliable method for establishing the causal agent in drug reactions. However, a topical provocation would be safer and easier to apply as a screening test especially when multiple drugs are suspected. Topical provocation tests with cephazolin $(10 \%$ in white petrolatum, lanolin-petrolatum and glycerine) as an open application which was described by Alanko remained negative in the previously reported case with linear FDE. A systemic provocation with cephazolin was not performed. ${ }^{4}$
In Turkey, $\approx 80 \%$ of FDE cases are co-trimozaxole related (unpublished data). In most of the studies reported from other countries, sulphamethoxazole is regarded as the main cause of co-trimoxazole allergy, but reactions to trimethoprim have also been reported. ${ }^{6-8}$ Usually, the offending drugs are determined by means of oral challenge. Topical provocation and positive reactions with co-trimoxazole are extremely rare in the literature. ${ }^{9-11}$ Alanko et al. pointed out that topical provocation with trimethoprim and sulphamethoxazole can best be obtained when DMSO is used as vehicle. ${ }^{9}$

To the best of our knowledge, our report represents the second linear FDE case in the literature. We would therefore point out that FDE should also be considered in the differential diagnosis of skin diseases with a linear distribution pattern, especially when there is a definite history of the lesions recurring in the same sites.

\section{I.Ü. Istanbul Tip Fakültesi,}

Dermatoloji Anabilim Dali,

E.ÖZKAYA-BAYAZIT 34390 Capa-Istanbul, Turkey

Email: bayazit@turk.net

\section{References}

1 Sehgal VN, Gangwani OP. Fixed drug eruption. Current concepts. Int J Dermatol 1987; 26: 67-74.

2 Sowden JM, Smith AG. Multifocal fixed drug eruption mimicking erythema multiforme. Clin Exp Dermatol 1990; 15: 387-8.

3 Thankappan TP, Zachariah J. Drug-specific clinical pattern in fixed drug eruptions. Int J Dermatol 1991; 30: 867-70.

4 Sigal-Nahum M, Konqui A, Gaulier A et al. Linear fixed drug eruption. Br J Dermatol 1988; 118: 849-51.

5 Grosshans E, Marot L. Blaschkite de l'adulte. Ann Dermatol Venereol 1990; 117: 9-15.

6 Kauppinen K, Stubb S. Fixed eruptions: causative drugs and challenge tests. Br J Dermatol 1985; 112: 575-8. 


\section{Livedoid skin necrosis (Nicolau syndrome) due to triple vaccine (DTP) injection}

SIR, Nicolau syndrome is a rare entity that consists of the development of cutaneous, subcutaneous, and even muscular necrosis with a livedoid pattern, shortly after intramuscular injection of many different drugs. We report the first case of this entity due to the intramuscular injection of diphtheria, tetanus and pertussis (DTP) vaccine.

A 3-month-old boy, without any remarkable past medical history, received the first intramuscular dose of vaccine against DTP in the anterior aspect of his left thigh. Immediately after the injection, the child showed intense irritability, probably related to local pain. An oedematous, pale plaque appeared at the injection site, and he was consequently admitted to our hospital. Three hours after the injection, the lesion had evolved into a livedoid purplish patch with dendritic extensions. The child was otherwise in general good health and routine laboratory examinations showed no abnormalities. A skin biopsy specimen was obtained. Histological examination disclosed necrosis of the eccrine glands, and thrombosis involving vessels of medium and small size of the reticular dermis without vasculitis. Twenty-four hours later the lesion was a welldefined, reticulate, violaceous patch (Fig. 1). The lesion was treated with local disinfection and topical mupirocin ointment. Progressively, three small eschars appeared and on the 10th day he was discharged. The general status of the child remained unaltered throughout the evolution. After 1 month, the lesion had completely healed leaving a slightly atrophic scar. The second dose of DTP was administered at the sixth month of life without immediate or delayed untoward reactions.
In the 1920s, livedoid skin necrosis was a well-known adverse effect of bismuth salts routinely used for the treatment of syphilis. ${ }^{1-3}$ Later, the phenomenon was related to intramuscular injection of antirheumatic preparations containing phenylbutazone associated or not with other anti-inflammatory agents, local anaesthetics (lignocaine), antihistamines (diphenhydramine), corticosteroids (triamcinolone), or vitamin B complexes (cyanocobalamin). ${ }^{4}$ It has also been described, as isolated cases, with antibiotics such as sulphonamides, benzatine penicillin, procaine penicillin G, pyrazolone, chlorpromazine, camphor-quinine combinations, phenobarbitone, recombinant interferon- $\alpha$ and a mixture of sedatives (meperidine, promethazine and chlorpromazine). ${ }^{5}$

Multiple pathogenic mechanisms have been proposed. The most reasonable hypothesis points to a vascular origin. Embolia cutis medicamentosa would be the end result of intra-arterial or periarterial injection of the offending drug, with subsequent arterial vasospasm and cutaneous necrosis with a livedoid pattern. Experimental animal models have shown that intraor perivascular injections can produce thrombosis or vasospasm, followed by inflammation of the vessel wall. Complete destruction of the vessel and necrosis of irrigated tissues may ensue. ${ }^{6}$ Hence, this syndrome should be considered as a consequence of direct trauma or irritation of vascular structures. Thus, elicitation of a new episode of livedoid skin necrosis after a further dose of the causative drug is not to be expected, as it would be if an immunoallergic mechanism were operating. Moreover, experimental studies have not provided data supporting the immunological hypothesis. ${ }^{7}$ Nevertheless, in spite of the traumatic/irritative origin being the most feasible, experimental
Figure 1. Reticulate, violaceous patch is evident on the anterior aspect of the left thigh, $24 \mathrm{~h}$ after the injection

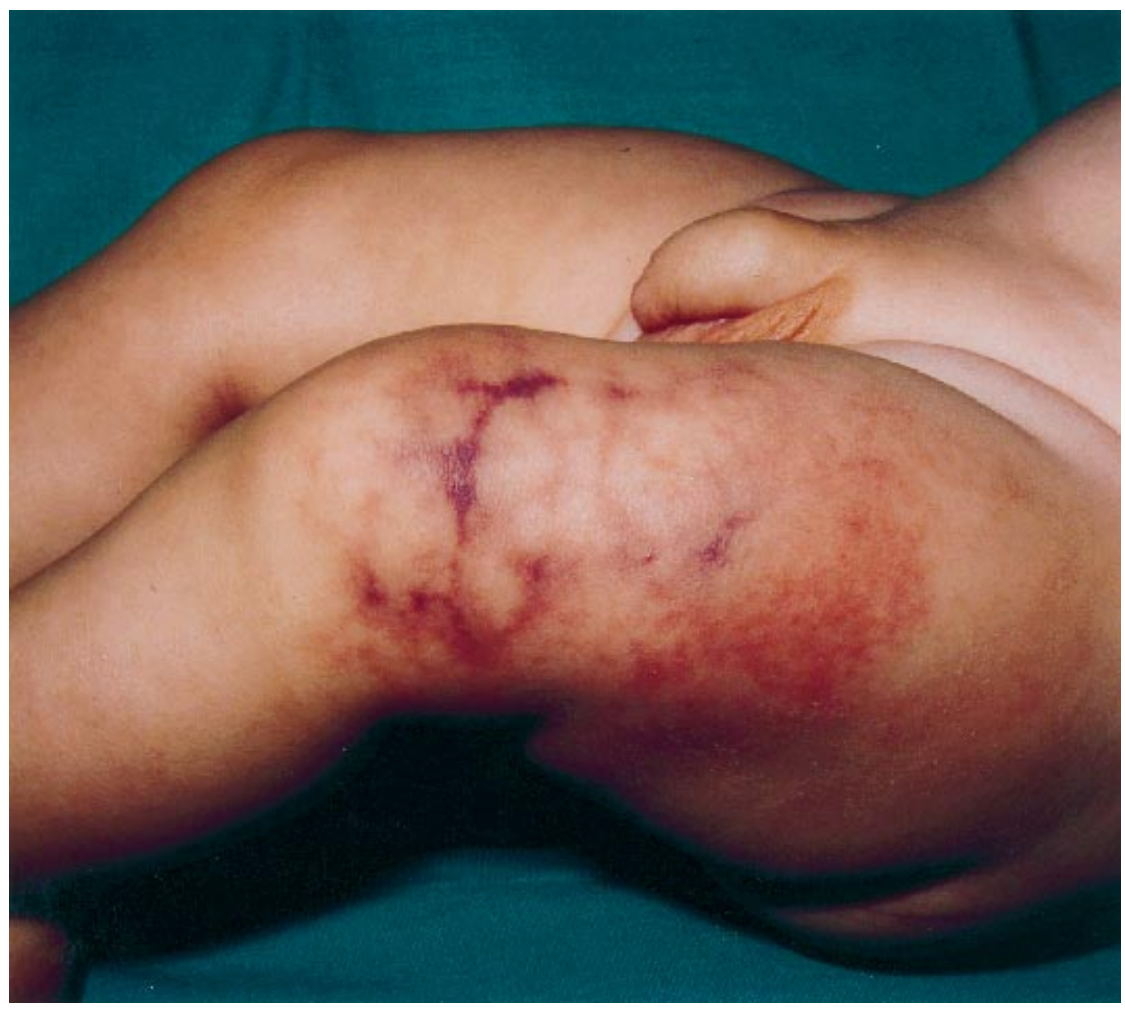

(C) 1997 British Association of Dermatologists, British Journal of Dermatology, 137, 1011-1031 
data suggesting some relation with injection technique ${ }^{8}$ and $\mathrm{pH}$ of the injected solution ${ }^{7}$ are lacking.

This patient is, to our knowledge, the youngest child to suffer from livedoid skin necrosis and the first case due to injection of DTP. None the less, it is unexplained why embolia cutis medicamentosa is so rare in children, as almost all children in the world are currently vaccinated against DTP by intramuscular injection. In our case, the second dose did not reproduce this adverse effect, suggesting that immunological or allergic factors do not play any significant part.

Department of Dermatology and *Pathology, Hospital del Niño Jesús,

Avda Menéndez Pelayo 65,

E.NAGORE

A.TORRELO

28009 Madrid, Spain

I.GONZÁLEZ-MEDIERO*

A.ZAMBRANO

\section{References}

1 Freudenthal W. Lokales embolisches Bismugenol Exanthem,
Sitzungsbericht des Schlesischen Dermatologischen Gesellschaft vom 24 November, 1923. Geschlechtskr 1924; 11: 400.

2 Nicolau P. Dermite livédoïde et gangréneuse de la fesse consécutive aux injections intramusculaires de la syphilis. Ann Venereol Mal Venereol 1925; 20: 321.

3 Gay Prieto J. Dermitis livedoide y necrótica debida a una embolia arterial bismútica. Actas Dermosifiliogr 1930; 23: 123-30.

4 Bork K. Aseptic necrosis after intramuscular injection (embolia cutis medicamentosa). In: Cutaneous Side Effects of Drugs. Philadelphia: W.B.Saunders, 1988; 364-9.

5 Faucher L, Marcoux D. What syndrome is this? Nicolau syndrome. Pediatr Dermatol 1995; 12: 187-90.

6 Brachtel R, Meinertz T. Local skin necrosis after intramuscular injection-experimental animal studies. Arch Dermatol Res 1977; 258: 281-8.

7 Müller-Vahl H, Pabst R. An animal model for aseptic necroses after intramuscular injections. Int J Tissue React 1984; 6: 251-4.

8 Svendsen O. Intramuscular injections and local muscle damage: an experimental study of the effect of injection speed. Acta Pharmacol Toxicol 1983; 52: 305-9. 